\title{
UNSHROUDING EFFECTS ON DEMAND FOR A COSTLY ADD-ON: EVIDENCE FROM BANK OVERDRAFTS IN TURKEY
}

\author{
Sule Alan \\ Mehmet Cemalclar \\ Dean Karlan \\ Jonathan Zinman \\ Working Paper 20956 \\ http://www.nber.org/papers/w20956 \\ NATIONAL BUREAU OF ECONOMIC RESEARCH \\ 1050 Massachusetts Avenue \\ Cambridge, MA 02138 \\ February 2015
}

We thank Yapi Kredi staff for their cooperation; Michael Grubb, Ben Keys, David Laibson, Eva Nagypal, Josh Schwartzstein, Andrei Shleifer, and audiences at Boston College, Harvard/MIT, Kellogg (Finance), LSE, UCL, University of Maryland, University of Virginia, the Federal Reserve Bank of Philadelphia, the CFPB Research Conference, and the NBER Law \& Economics group for comments; and Benni Savonitto, Glynis Startz, and Zachary Groff for research management and analysis support. The findings, interpretations and conclusions presented should not be attributed in any manner to Yapi ve Kredi Bankasi A.S. All errors are our own.

NBER working papers are circulated for discussion and comment purposes. They have not been peerreviewed or been subject to the review by the NBER Board of Directors that accompanies official NBER publications.

(C) 2015 by Sule Alan, Mehmet Cemalclar, Dean Karlan, and Jonathan Zinman. All rights reserved. Short sections of text, not to exceed two paragraphs, may be quoted without explicit permission provided that full credit, including (C) notice, is given to the source. 
Unshrouding Effects on Demand for a Costly Add-on: Evidence from Bank Overdrafts in Turkey

Sule Alan, Mehmet Cemalclar, Dean Karlan, and Jonathan Zinman

NBER Working Paper No. 20956

February 2015, Revised January 2016

JEL No. D12,D14,G02

\section{ABSTRACT}

The pricing and advertising of tied add-ons and overages have come under increasing scrutiny. Working with a large Turkish bank to test SMS direct marketing promotions to 108,000 existing holders of "free" checking accounts, we find that promoting a large discount on the $60 \%$ APR charged for overdrafts reduces overdraft usage. In contrast, messages mentioning overdraft availability without mentioning price increase usage. Neither change persists long after messages stop, suggesting that induced overdrafting is not habit-forming. We discuss implications for interventions to promote transparency in pricing and advertising, and for models of shrouded equilibria, limited attention, and salience.

Sule Alan

Department of Economics

University of Essex, Wivenhoe, Colchester

CO79AX, UK.

salancrossley@gmail.com

Mehmet Cemalclar

Yapi Kredi Bank A.S.

Istanbul, Turkey

mehmet.cemalcilar@yapikredi.com.tr

\author{
Dean Karlan \\ Department of Economics \\ Yale University \\ P.O. Box 208269 \\ New Haven, CT 06520-8629 \\ and CEPR \\ and also NBER \\ dean.karlan@yale.edu \\ Jonathan Zinman \\ Department of Economics \\ Dartmouth College \\ 314 Rockefeller Hall \\ Hanover, NH 03755 \\ and NBER \\ jzinman@dartmouth.edu
}




\section{Introduction}

Many inexpensive base goods have expensive add-ons tied to them. Examples include expensive overdraft credit tied to "free" checking accounts, printer cartridges and printers, luggage fees and airline tickets, and dealer-supplied maintenance and automobiles. A closely related practice is multi-part tariffs with overages - penalty pricing — which is again common in disparate industries; e.g., financial services, telecommunications, health care, and electricity.

Theorists, empiricists and policymakers are scrutinizing the pricing and advertising of tied add-ons and overages as potentially deceptive and inefficient. Yet empirical evidence is lacking on key questions posed by the theoretical literature, such as whether consumers underestimate add-on costs, ${ }^{2}$ whether firms have incentives to shroud add-on prices (Gabaix and Laibson 2006; Heidhues, Koszegi, and Murooka 2014), how consumers allocate attention to add-ons (Bordalo, Gennaioli, and Shleifer 2015; Grubb 2015), and how quickly consumer learning about add-ons breaks a shrouded equilibrium (Gabaix and Laibson 2006; Heidhues, Koszegi, and Murooka 2014).

We provide empirical evidence on these questions from a direct marketing randomized experiment on checking account overdrafts, a prevalent and economically important example of a tied add-on and overage that has helped motivate much of the recent theoretical work. An overdraft occurs if the checking account holder initiates a transaction that makes her balance negative, or more negative. Checking accounts in much of the world moved to a "free if nonnegative balance, very expensive if in overdraft" equilibrium during the 1990s, with overdraft revenue from fees and interest charges replacing monthly subscription fees as the major source of explicit income from checking accounts. In the US, banks collect more than $\$ 10$ billion in overdraft revenue annually (sources: CFPB, Moebs, SNL Financial). In the UK, banks derive almost as much income from overdrafts as from re-investing checking account deposits (Competition and Markets Authority 2014). Overdraft practices have also triggered several recent regulatory actions in the US and the EU. In Turkey, the site of our

\footnotetext{
${ }^{2}$ Behavioral industrial organization models make a variety of different assumptions about the cause of incorrect expectations about future consumption; see Spiegler (2011) for a review. In terms of the models most closely related to our setup, Gabaix and Laibson (2006), Heidhues, Koszegi, and Murooka (2014), and Bordalo, Gennaioli, and Shleifer (2015) assume that some consumers underestimate a reduced-form add-on cost that, in our setting, is the product of the price of overdrafts and the likelihood that one enters the overdrafting state: checking account balance $<0$. Grubb (2015) assumes that consumers know the price but underestimate the likelihood of overdrafting, because they underestimate their cost of attention to balances. See also Grubb (2009).
} 
experiment, the post-experiment announcement of a binding price ceiling on overdrafts was immediately followed by a $1.4 \%$ reduction in bank share prices, with a $2.1 \%$ drop for the most overdraft-reliant bank, highlighting the importance of overdrafts as a profit center for banks.

Descriptive evidence suggests that the bank overdraft market is a prime example of a shrouded equilibrium where firms lack incentives to draw attention to, or compete on, add-on prices. Despite the economic importance of overdrafts, banks rarely market these services, at least at the customer acquisition stage (General Accounting Office 2008; Competition and Markets Authority 2014). ${ }^{3}$ Post-acquisition, banks in some markets, including the site of our experiment, have blurred the line between positive and negative balances for consumers by reporting an available-to-withdraw figure that adds the available credit amount to the checking account balance, and by making information on disaggregated balances and finance charges more difficult to find than the aggregate available balance. On the consumer side, overdrafts happen passively in the sense that they are triggered in the course of checking account usage rather than by separate transactions where a consumer explicitly draws from a line of credit: they are plausibly low "exposure" and likely to be ignored or forgotten (Bordalo, Gennaioli, and Shleifer 2015). Some descriptive data are consistent with consumers overdrafting when they could have used much cheaper available credit on credit cards (Stango and Zinman 2009), underestimating overdraft likelihood and prices (Armstrong and Vickers 2012; Stango and Zinman 2014), and experiencing “bill shock” (Grubb 2015).

Nevertheless there are reasons to doubt the descriptive power of shrouding models. Stango and Zinman (2014) finds that low balances $(<\$ 100)$ are common but not typically followed by overdrafts in a US sample, and that many checking account holders report a willingness to pay a market price (e.g., a \$25-\$30 fee) to settle even a small-dollar overdraft. The bulk of overdraft costs are paid by a small number of checking account holders who overdraft repeatedly (Bakker et al. 2014; Financial Conduct Authority 2014), raising the broader question of whether experience unshrouds or at least bounds the distortions or duration of a shrouded equilibrium. ${ }^{4}$ Indeed, Heidhues, Koszegi, and Murooka (2014) notes that the profitability of high add-on prices is 'limited by consumers' ex-post demand

\footnotetext{
${ }^{3}$ Casual empiricism suggests that some banks are now starting to market low-cost or no-overdraft products in the U.S., perhaps in response to recent regulations and ongoing regulatory pressure.

${ }^{4}$ Gabaix and Laibson (2006, Section III.A) speculates that learning causes shrouding to disappear, eventually, despite potential countervailing dynamic forces.
} 
response to add-on prices” (p. 11), raising the possibility that, at the customer level, the firm wants to shroud at the acquisition stage but then unshroud while cutting the price of the addon. Practices in our setting seem consistent with some degree of unshrouding, as we discuss below.

In short, empirical evidence on what drives overdraft pricing, advertising, and usage is mixed and largely descriptive. More broadly, empirical work on tied add-ons and overage pricing is still in its early stages.

Yapi Kredi (YK), one of the largest banks in Turkey, sought to learn more about the overdraft market and its optimal strategy for pricing and marketing the product (which is branded as the "Flexible Account”). In particular, YK was interested in understanding whether its past pricing and advertising content tactics are effective in increasing demand, and if not why not. YK's interest rate (60\% APR) and product design was in line with standard practices and regulations. As is common in overdraft markets, the product was priced expensively relative to seemingly close substitutes (like credit cards in Turkey), and disproportionally to credit risk (as found recently by Turkish regulators and courts).

We worked with YK to design randomized experiments to distinguish between neoclassical and behavioral models of add-on pricing and advertising. YK implemented the experiments by randomly varying the messaging and pricing (promotional offers) it sent, via SMS, to 108,000 existing checking account clients, from September-December 2012. These clients are likely representative of a substantial population of marginal overdrafters in Turkey, and they share key characteristics with "banked” populations in both more- and lessdeveloped countries.

The design (summarized in Figure 1) produces random variation, across clients and over time, in prices and in messaging content, frequency, and duration. Our tests rely on comparisons across different treatment groups, since banks in this market are typically doing some sort of SMS-based promotions at any point in time: the equilibrium is frequent direct marketing. ${ }^{5}$

\footnotetext{
${ }^{5}$ The bank also created a no-message comparison group of 39,367 existing checking accounts, and we use these data to confirm that a sharp increase in overdrafting among the messaging groups that was contemporaneous with our experiment was likely indicative of market-wide forces rather than anything particular to our study (Figures 2a and 2b and Section 2.3).
} 
A question of ethics, raised frequently in seminars, is whether researchers should partner with a lender that is seeking to sell more high-interest rate loans. We think yes, in this circumstance as in many related experiments on microcredit where take-up is an outcome of interest, for four key reasons. First, the ethical concern here presumes that high-cost consumer credit harms consumers. We emphasize the presumption; extensive research on this question suggests that a different assumption is warranted-- (weakly) beneficial impacts for consumers (Zinman 2014; Banerjee, Karlan, and Zinman 2015). Second, YK’s advertising was truthful and its terms were competitive. Thus, combining the first and second points, the experiment was not trying to convince consumers to accept a bad deal in either absolute terms or compared to market alternatives. Third, YK was going to test advertising and messaging in its upcoming campaign anyhow; we helped convince bank management to include price discounts and unshrouding, and hence our participation made prices lower and more prominent on average. Fourth, YK agreed that the results would be disseminated publicly to benefit regulators and further scientific knowledge (and likewise in this spirit, the academic coauthors had unrestricted intellectual freedom to report the results regardless of what they were).

Our first key test offers a 50\% discount on the overdraft interest rate: “... we will give you back half of your Flexible Account's accrued interest...” This message reduces overdraft usage by about $5 \%$ relative to overdraft messages that do not mention price, and by about $2 \%$ relative to all messages that do not offer the discount. Additional results suggest that moreintense messaging about the overdraft discount-higher-frequency and/or longer duration messaging - at least weakly intensifies this perverse effect. These are striking findings: offering a price reduction on a commodity reduces demand for that commodity. ${ }^{6}$ This is all the more striking given our sample of existing customers; as noted above, firms probably have lesser incentives to shroud at this post-acquisition stage than at the customer acquisition stage.

Our second key test promotes overdraft availability without mentioning price: “We remind you that,... you have a Flexible Account at Yapi Kredi with [customfill] TL limit...”. This message increases overdraft usage relative to messages that do not mention overdraft at

\footnotetext{
${ }^{6}$ Our finding is reminiscent of the Hsee (1998) finding explained in Bordalo, Gennaioli, and Shleifer (2015). In isolation, people have higher hypothetical willingness to pay for a dinner set with 24 plates than for one with $>24$ intact plates but a few broken ones. But in a pairwise choice people prefer the set with $>24$ intact plates. Having said that, we do not actually offer consumers in our sample a pairwise choice between more-expensive and less-expensive overdrafts.
} 
all, by about $4 \%$, and by about $5 \%$ relative to messages offering the overdraft interest discount. Sending more overdraft availability messages further increases demand.

Our third key test finds that all treatment effects dissipate over time; e.g., five months after all treatments ended we no longer reject null hypotheses of no effects. This runs counter to the assertion by some policymakers that overdrafts are habit-forming (Financial Conduct Authority 2014).

Our three key results are consistent with models of shrouded equilibrium a la Gabaix and Laibson (2006), and also suggest a role for salience a la Bordalo, Gennaioli, and Shleifer (2015), as we discuss in detail in Section 5. ${ }^{7}$ In summary, our results support: (1) the key modeling assumption that consumers tend to underestimate add-on costs; (2) the key prediction that firms lack incentives to unshroud; (3) a key prediction of Bordalo, Gennaioli, and Shleifer (2015) that consumers respond differently when advertising highlights different add-on attributes. Our results reject habit formation in induced overdrafting, suggesting that consumer learning about overdrafts is slow (due to rapid depreciation of knowledge and/or attention), unshrouding is costly, and hence that transitions from shrouded to unshrouded equilibria may be slower than conjectured by Gabaix and Laibson (2006) and Heidhues, Koszegi, and Murooka (2014). We also discuss competing interpretations (rational inattention, and a mistrust story), and why they do not provide as complete an explanation of our setting and results.

Our paper informs several other literatures on limited attention, salience, and advertising. Our results provide insight into what comes to mind and what does not (Bordalo, Gennaioli, and Shleifer 2013; Eliaz and Spiegler 2011; Gabaix 2014; Hanna, Mullainathan, and Schwartzstein 2014; Karlan et al. Forthcoming). They suggest that price promotions have attention effects that can be perverse from the promoter's perspective, thereby adding evidence to literatures on the psychology of incentives (Gneezy and Rustichini 2000; Kamenica 2012) and price changes (Hastings and Shapiro 2013) that have not yet focused much on shrouded prices. Our results are consistent with results from other domains suggesting that consumers respond differently to base prices versus add-on prices (Anagol

\footnotetext{
${ }^{7}$ Note however that our study does not map directly to most shrouding models, as most shrouding models focus on competition at the customer acquisition stage rather than the post-acquisition setting we have here.
} 
and Kim 2012; Brown, Hossain, and Morgan 2010; Chetty, Looney, and Kroft 2009). ${ }^{8}$ Relatedly, our findings contrast with those in Ferman (Forthcoming) and Elizondo and Seira (2014), both of which find little impact of messaging that makes the base price of highinterest credit cards more prominent in Brazil and Mexico. Our results are broadly consistent with prior work finding that advertising content can have important and surprising effects on decisions about expensive debt (Bertrand et al. 2010), and that messaging from banks can change the behavior of existing customers (Cadena and Schoar 2011; Kast, Meier, and Pomeranz 2014; Karlan, Morten, and Zinman Forthcoming). Our results on the long-run effects of short-run messaging complement the literature on the dynamics of learning and/or attention regarding add-on charges (Agarwal et al. 2013; Ater and Landsman 2013; Haselhuhn et al. 2012; Stango and Zinman 2014), ${ }^{9}$ may help explain why advertising is so prevalent (repeated exposure matters), and suggest that short-run behavior changes do not necessarily induce learning or greater sophistication about attention among marginal consumers (Schwartzstein 2014). ${ }^{10}$

\section{Setting: The Overdraft Market in Turkey}

Our discussion here focuses on our partner bank, Yapi Kredi (YK), and the Turkish overdraft market. As noted in the Introduction, our setting has many similarities to overdraft markets in other countries like the US and UK, with a key difference being substantially lower prices in Turkey (60\% APR vs. \$25-\$40 per transaction fees for very small and shortterm loans). For details on overdraft markets in the US and Europe see, e.g., government

\footnotetext{
${ }^{8}$ We do not actually observe price sensitivity to the base price in our setting. But given our result that cutting overdraft prices depresses overdraft demand, we can infer differential sensitivity to base and add-on prices simply by assuming that cutting the base price would not decrease demand for checking accounts.

${ }^{9}$ Stango and Zinman (2014) is probably the most closely related empirical paper to ours. SZ uses quasi-experimental variation in survey content, in a market research panel in the U.S., to identify effects and dynamics of attention to overdraft fees. Similar to here, SZ finds that an attention shock mentioning overdraft costs reduces overdraft usage, and that repeated attention shocks cumulate to some extent, although they depreciate more quickly in our setting. Aside from the obvious differences between the two study designs - market research surveys versus bank advertising as attention shocks, quasi-random versus random variation, US versus Turkey-there are at least two other key differences. First, we have randomly assigned price variation. Second, our treatments include some messages that mention the overdraft service but not its cost. These differences lead to the surprising new inferences that bringing overdrafts to mind increases demand, but bringing the price of overdrafts to mind, even if accompanied by a discount, lowers demand.

${ }^{10}$ See also Manoli and Turner (2015) on the rapid depreciation of information effects regarding the Earned Income Tax Credit.
} 
reports (Bakker et al. 2014; Competition and Markets Authority 2014; Financial Conduct Authority 2014; General Accounting Office 2008), and Stango and Zinman (2014). ${ }^{11}$

\subsection{Retail Banking and the Economic Importance of Overdrafts}

Turkey's retail/consumer banking industry is concentrated. Only about 30 banks are licensed to take deposits, and the largest five banks have greater than $50 \%$ market share. ${ }^{12}$ Yapi Kredi (YK) is in the top five based on both total assets and number of branches. In recent years the Turkish market has become known for innovation in retail banking, with one large bank rolling out the largest biometric ATM network in the region, and another large bank becoming the first bank in the world to make money transfers possible on Facebook. Turks have the highest rate of mobile banking in Europe among internet users, at around $50 \%$, according to a 2013 ING survey.

As in many other countries, overdraft services are an important profit source for banks. After the Turkish Central Bank halved the interest rate allowed on overdrafts at the end of May 2013, bank share prices fell 1.4\%, with that of the most overdraft-reliant bank falling by $2.1 \% .^{13}$

\subsection{Overdraft Practices}

The focus of our experiment is a checking account overdraft product with features that were standard in Turkey (and throughout the world) during our study period. The product is an unsecured line of credit that allows qualifying customers to overdraw their account (i.e., to hold a negative balance), at a cost of $60 \%$ APR on outstanding credit (about 50\% real after adjusting for inflation). Credit card APRs tend to be substantially lower. The bank approves about 55\% of checking account customers for overdraft privileges, with credit limits that vary based on underwriting but are typically lower than other unsecured credit products. Approved credit lines were opened on an opt-out basis during our study. Customers then tap the line by initiating a debit transaction that exceeds the available balance in the checking account. The line is automatically tapped by such debits - there is no opt-in on a per-transaction basis-- and

\footnotetext{
${ }^{11}$ For recent policy developments in the US and EU, see, e.g., FDIC Supervisory Guidance warning banks about about risks of "excessive use" of overdrafts by customers and "maximizing fees" by banks, Dougherty (2014), and the European Parliament's Directive on Payment Accounts (issued April 2014).

${ }^{12}$ As of September 2012 top branch bank had 1,510 branches, and the fifth largest bank had 949, out of 10,241 total. Of this total the top five owned 5,663 branches (source: http://en.wikipedia.org/wiki/List_of_banks_in_Turkey, accessed 10/22/2014).

${ }^{13}$ http://www.reuters.com/article/2013/05/27/markets-turkey-idUSL5N0E81DG20130527 .
} 
negative balances begin accruing interest immediately. By law, any inflow to the checking account is automatically allocated first toward paying off overdraft credit. If inflows are not sufficient to clear the balance by the end of the statement date (four weeks), the bank sends a notice and gives the customer about two weeks to pay at least the accrued interest. If the customer fails to make the required payment after 60 days, the bank freezes the overdraft line.

Overdrafts have attracted regulator and researcher scrutiny because they-and their prices-are rarely featured at the customer acquisition stage, and often not fully disclosed post-acquisition. Pre-acquisition, indeed, we are not aware of any mass marketing campaigns promoting overdraft usage during our sample period in Turkey. Regulators found that when banks do communicate with consumers, they often fail to provide mandated disclosures or shroud them. Given that communication from banks is common in Turkey, regulators are interested in issues of transparency for these communications. YK is a case in point in the sense that it sought guidance to measure and improve the effectiveness of direct-messaging and price promotion strategies that it had tried previously. This sort of price advertising and competition is consistent with at least partial unshrouding, although this did not keep the Competition Authority from finding that banks were benefiting from substantial markups over risk-based prices (Section 2.4).

Indeed in many respects post-acquisition communications seemed quite consistent with a shrouded equilibrium during our sample period. Customers lacked easy access to information on their own overdraft usage and charges. Banks did not issue monthly statements as a matter of course, due to the unreliable snail-mail system, and electronic notifications of overdraft usage did not mention the interest rate. Electronic banking was and is the dominant channel for customers getting information on their accounts, and information on overdraft usage was folded into the customer's main transaction record rather than disaggregated. The transaction record would specify the amount charged, but not the interest rate. Landing pages - the first screen the customer sees after logging in-- would even obscure whether overdraft was being used, in the sense of presenting the customer's balance based on "available-to-withdraw" (including credit line) instead of just the checking account balance. A customer seeking interest rate information would need to navigate through several different screens to find interest rate information — “multiple clicks”, in user-interface parlance-or contact a customer service representative. 


\subsection{Overdraft Users and Usage in Turkey}

Who overdrafts? In Turkey there is not much data on the characteristics of overdrafters (e.g., our data lack information on education or income), but there are some clues. Over half of Turkey's population is unbanked, according to a 2012 World Bank report. Beyond that many checking account holders are not approved for overdraft lines of credit due to credit risk that banks cannot price. These facts suggest that overdrafters are drawn from the upper half or third of the income distribution in Turkey, although not from the uppermost percentiles, who presumably have the wealth and access to cheaper credit that would tend to render overdrafting unlikely and/or relatively unattractive.

Our sample overdrafts frequently in the ten months after our experiment started, despite having been selected for the experiment based on infrequent overdraft activity prior to the experiment (Section 3.2; Table 1). 45.8\% of our sample overdrafts at least once between September 1, 2012-June 30, 2013, and in any given month 15-24\% of our sample overdrafts. The sharp increase in overdrafting from baseline to (post-) experiment is probably not due to mean reversion, as overdrafting tends to be strongly serially correlated month-to-month. Rather, discussions with YK and its regulators point to a marketwide increase driven by monetary policy and widespread seasonal credit promotions around the end of Ramadan. This pattern is evident both in aggregate data and in YK's customer base. YK held back a nomessage group of 39,000 from our experiment, and Figures 2a and 2b show similar trends in overdraft usage for this group compared to our experimental group of $108,000 .{ }^{14}$

The mean amount of finance charges paid over the ten months is $30.82 \mathrm{TL}$ ( $1 \mathrm{TL}=\$ 0.56$ USD during our sample period), with a $95^{\text {th }}$ percentile of $228.08 \mathrm{TL}$.

\subsection{Policy Postscript}

As noted above, overdraft practices have been attracting legal scrutiny around the globe. In July 2013, seven months after our experiment ended, the Turkish Competition Authority fined 12 banks for price-fixing on loans, including overdrafts. On May 27, 2013, the Turkish Central Bank imposed a binding price ceiling on overdraft APR. Turkish regulators have also

\footnotetext{
${ }^{14}$ YK applied somewhat different and not entirely reproducible filters in selecting the no-message comparison group, so we do not use this group as a pure control group. Creating a pure control group was not a point of emphasis at the design and implementation stages of the experiment, since the equilibrium was clearly one of extensive direct-messaging and hence the mapping of message vs. nomessage comparisons to theory is less clear than comparisons across different promotions.
} 
focused on marketing and communications since our experiment ended, pressuring and working with banks to make overdraft usage, pricing, and costs more transparent.

\section{Experimental Design, Sample and Data}

\subsection{Experimental Design and Implementation}

Figure 1 summarizes the experimental design and details the script of each message variant. The field experiment randomly assigns message content, frequency, and duration, as well as promotional offers on overdraft, debit card, and automated debit (for bill payment), to a sample of 108,000 checking account holders (we describe the sample in Section 3.2). YK did not send this sample any other promotional communications during this campaign. The only other communications YK sent to this sample were monthly account statements.

YK sent the messages by SMS, which is the most common way banks communicate with their clients in Turkey (91\% of Turkish adults have a cell phone, for one of the highest penetration rates in the world). As noted above, it is also common for clients to use their phone to access banking services; e.g., Turkey has the highest ratio of mobile banking users to Internet users in Europe.

YK began the experiment by sending half of the sample an "overdraft availability reminder” message on August 30, 2012 that mentions the overdraft service and credit line but nothing about its cost. ${ }^{15}$ This first randomization is not crucial for testing our main hypotheses; it served primarily as a pilot for the subsequent randomizations and also allows us to test for a heterogeneous treatment effect suggested by some of the motivating theoretical models (Section 4.3).

YK continued the experiment on September 15, 2012 by sending each person in the sample one of six randomly assigned messages: (1) 50\% ( $n=53,953)$ received an "overdraft

\footnotetext{
15 "We remind you that, for your immediate cash needs, you have a Flexible Account at Yapi Kredi with [custom fill]TL limit. Have a nice day." One might think of this message as a "reminder" because the bank's policy and Turkish law require upfront disclosure of the overdraft features and pricing. However, given that the service is offered on an opt-out basis, and that our motivating questions concern shrouding, we allow for the possibility that this message provides new information rather than being a simple reminder. We explore this in Section 4.3.
} 
interest discount" message; ${ }^{16}$ (2) Among the 53,953 clients sent the overdraft interest discount, one third $(n=17,981)$ also received information about an auto-debit discount ${ }^{17}$ in the message, one-third $(n=17,995)$ also received information about a debit card discount ${ }^{18}$ in the message, and one-third $(n=17,997)$ received no further information beyond the overdraft interest discount; (3) among the 54,047 clients not sent one of the above overdraft interest discount messages, one-third $(\mathrm{n}=18,021)$ received information about the auto-debit discount only, ${ }^{19}$ one-third $(n=17,983)$ received information about the debit card discount only, ${ }^{20}$ and one-third $(n=18,043)$ received the overdraft availability reminder message described above. ${ }^{21}$

A frequency randomization determined whether YK repeated the September 15 message frequently (every 10 days), less-frequently (every 20 days), or not at all during the campaign period. A duration randomization determined whether the price promotion(s) or overdraft availability reminder, and any related messaging subsequent to September 15, lasted until November 15 or December 15.

Note that YK sent at least one message to everyone in our sample during the experiment. YK preferred this design choice because, like other banks, it often sends promotional and reminder messages to its customers and thought it would be counterproductive to scale back directed advertising to zero. The research team preferred this design- placebo communications rather than pure control-because any contact from YK could trigger the customer's attention and affect her usage of YK products. ${ }^{22}$

\footnotetext{
16 "Use your Yapi Kredi Flexible Account and we will give you back half of your Flexible Account's accrued interest between now and [November/December] 15...”

17 "Authorize automatic bill payments from your account before [November/December] 15, receive up to a maximum of 30TL WP. Use your Flexible Account between now and [November/December] 15, and we will give you back half of your accrued interest as WP." Note that "WP" refers to reward points, which are easily redeemable at point-of-sale using the account's debit card; anecdotally, most of the bank's customers view them as equivalent to cash. To sign-up for auto-debit, most people either go on-line or use telephone banking, and do not go into a branch to enroll a payment.

18 "Use your Yapi Kredi debit card and earn 5\% of your shopping, up to 25TL WP, between now and [November/December] 15. Use your Flexible Account between now and [November/December] 15, and we will give you back half of your accrued interest as WP."

19 "Authorize automatic bill payments from your account before [November/December] 15, receive up to a maximum of 30TL WP."

20 "Use your Yapi Kredi debit card and earn 5\% of your shopping, up to 25TL WP, between now and [November/December] 15 as WP."

21 "We remind you that, for your immediate cash needs, you have a Flexible Account at Yapi Kredi with [customfill] TL limit...”

${ }^{22}$ A closely related way of framing our interest in placebo communications is that frequent directmessaging is the equilibrium, and we thought that the experiment would link more tightly to theory if the only deviations from equilibrium were around unshrouding.
} 


\subsection{Baseline Data on Sample Characteristics, and Balance Checks}

The bank sought to promote overdraft usage among existing clients who it deemed most likely to be close to the margin of overdrafting. To this end it selected customers for the experiment based on the following criteria: had the overdraft service feature in place already, had an active cell phone, maintained an average total deposit account balances $<5,000 \mathrm{TL}$ over the three months prior to the start of the experiment (May-July 2012), had not used the overdraft service (to a first approximation) during the prior three months. ${ }^{23}$ Many of these customers did have some prior experience with the product however. Our pre-treatment data go back as far as September 2011, and from September 2011-April 2012 18.4\% of our sample overdrafted at least once, with an average daily balance of 4.42TL (SD 23.51, Max 940.47) among these accountholders. For comparison, 31\% of our sample overdrafted at least once during the experiment (September 15-December 31), with an average of 2.77 overdrafts during that period (SD 6.05, Max 27) and an average daily balance of 26.85TL (SD 77.97, Max 2696.58).

Table 1 summarizes the baseline data available to us (Column 1) and checks balance across treatment assignments (Columns 2 -10). In terms of demographics, we only have information on gender ( $29 \%$ female), the city of residence (28\% Istanbul, $23 \%$ outside the four largest cities), and marital status (57\% married). This information is collected by the bank at the account opening stage and can be updated later by the client. Besides pretreatment data on overdraft usage (described above and in Table 1), we also have data on the other behaviors targeted by the experiment: debit card usage and automatic debits for bill payments. We stratified on all of these baseline variables and the last column confirms that none of them is correlated with treatment assignment, by regressing each row variable on the treatment assignments indicated Columns 2-10.

\subsection{Follow-up data}

YK provided us with data on overdraft usage, debit card usage, direct debit authorizations, and deposit account balances, at the account-month level, from September 1, 2012 through the end of June 2013 (although we do not use the June 2013 due to the binding price cap imposed at the end of May 2013). In addition to the monthly data, YK provided us

\footnotetext{
${ }^{23}$ Other sample frame criteria were: owned a YK checking account for at least a year and were in good standing; had a debit card linked to the YK checking account, had no more than three auto-pays already set up.
} 
with daily data on overdraft usage for the experimental period: September 15-December 15, 2012. We use this data to construct outcome variables for estimating the short-run and longer-run treatment effects detailed in the next section.

\section{Specifications and Results}

We estimate OLS regressions at the level of YK's randomizations - the checking account, indexed by $\mathrm{i}$ - and a time block that corresponds to either during- or post-experimental advertising (indexed by t):

(1) $Y_{\mathrm{it}}=\mathrm{a}+\mathrm{B} T_{\mathrm{i}}+\mathrm{C} X_{\mathrm{i}}+e_{\mathrm{it}}$,

where $Y$ is some measure of a behavior targeted by the marketing campaign: overdraft usage, debit card usage, or an automatic debit for bill payment. In Tables 2 and 3 we measure outcomes over a time period designed to capture immediate/short-run treatment effects: $t$ covers September 15-December 31, since the bank sent everyone at least one promotional message starting September 15 and sent the last promotional messages on December 15 . Table 4 measures outcomes over the post-experiment time period: January 2013-May 2013.

$T$ is a vector of treatment assignments (see Figure 1), with $B$ the vector of estimated coefficients on those treatment variables. $X$ is a vector of the stratification variables used to block the randomization (see Table 1).

Our main tables define the treatment vector to test key predictions and features of models of shrouding and limited attention with the simplest possible presentation; in particular, we make use of additive specifications that enable us to keep the omitted treatment category consistent across columns within each table, and to facilitate inference about comparisons of theoretical interest: overdraft promotions that mention price vs. those that do not (rows 4-7 in Tables 2 and 4), and price promotions on other banking services that are bundled with overdraft discounts vs. those that are not (rows 2 and 4 in Table 3). The Appendix Tables present a more comprehensive set of results.

\subsection{Main Effects of Overdraft Promotions on Overdrafting, During Experiment}

Table 2 estimates the effects of the different overdraft promotions, on three different measures of overdraft usage, during the experimental time period (September 15-December 31, 2012). 
Row 4 shows our estimates of the effect of getting an overdraft interest promotion relative to getting the other overdraft-mentioning message- the availability message that does not mention price. Reading across columns one can see that this effect is negative-offering a lower price leads to lower demand - with estimates for two of the three demand measures having p-values $<0.01$. The extensive margin falls by 1.2 percentage points, and days with a balance falls by 0.16 , for declines of 4 and $6 \%$ relative to the sample means. Of course our additive specification is not the only way to scale or identify these effects; e.g., it is also interesting to compare the effect of getting an overdraft discount offer to all other messages, since this is another way to frame the bank's decision. These effect sizes (standard errors) are $-0.0065(0.0028)$ for $1 / 0$ overdraft usage, -0.0728 (0.0365) for days with overdraft balance, and -0.1057 (0.4688) for average overdraft balance. We discuss magnitudes in detail below but for now note that these and our other effect sizes are likely to be substantial in economic terms.

Rows 5, 6, and 7 decompose the perverse price effect into the overdraft discount only (row 5), and the overdraft discount bundled with discounts for auto-pay (row 6) or debit card use (row 7). These results suggest that the overdraft discount by itself does not depress demand; rather it is the bundled discounts that drive the perverse effect (see also Table 3, Columns 3-5, Rows 2 and 4). We examine whether this is a somewhat mechanical result: whether the auto-pay or debit card message motivated individuals to maintain larger bank account balances, which thus led to lower frequency of overdrafting. Appendix Table 1 Panel B shows that the auto-pay and debit card promotions do not lead to higher bank account balances. Lacking evidence for this sort of mechanical mechanism, we posit a salience mechanism: by bundling overdraft promotion with another account feature that can produce overdrafts, the consumer not only becomes increasingly aware of the price of overdraft, but is also reminded to monitor particular transactions more closely. ${ }^{24}$ This is consistent with Stango and Zinman (2014), which finds that survey questions about spending control, monitoring account balances, or other bank fees lead to overdraft reductions.

In all, Table 2 Rows 4-7 support a key prediction of shrouding models: drawing attention to the cost of a shrouded attribute reduces the demand for it (even, in our case, when offering

\footnotetext{
${ }^{24}$ These bundled messages are also longer than the single-discount messages, but if longer messages tax limited attention we would expect them to push treatment effects on overdrafting toward zero instead of further depressing demand. The idea is that getting a too-long message is akin to getting no message at all, since the recipient ignores the too-long message.
} 
a 50\% discount!). We confirm that this lower demand likely maps into lower profitability for the bank in Appendix Table 1, which shows that deposit account balances (checking + saving) do not increase to offset promotion costs and lost overdraft revenue with increased implicit interest. $^{25}$

Table 2 rows 1 and 3 identify our second key result: the effect of the overdraft availability message that does not mention costs or offer a discount. This message increases demand for overdraft relative to messages that do not mention overdraft, on the order of 1 percentage point in 1/0 usage, 0.1 days with an overdraft balance, and 1TL in average overdraft balance. These effects are consistent with the overdraft feature-and not just its cost-- being far from top of mind: reminding someone of its availability and quantity (the size of the credit limit) increases usage. (We discuss implications for theory and practice in Section 5.)

The magnitudes of the treatment effects in Table 2 are likely economically significant, for several reasons. First, they suggest that drawing attention to overdraft costs induces upwardsloping demand. Framed differently, it suggests that messaging about costs without offering a discount —as one might contemplate as part of a pure debiasing strategy-would depress demand even more. Second, the messaging here does not mention the level of costs- again as one might contemplate as part of a pure debiasing strategy like "Beware of overdrafts at $60 \%$ APR!” Instead YK offers to give back "half of the interest”. It seems plausible to think that messaging around the cost level might depress demand even more, particularly if consumers tend to underestimate add-on costs as assumed by shrouding models. Third, messaging costs are low, and hence bank strategy is sensitive to small changes in demand. Fourth, our estimates are in intention-to-treat (ITT) units, and we should keep in mind that some recipients may have ignored the messages and hence not actually been "treated". Treatment-on-the-treated effects might be more informative for mapping the steady-state implications of our results, and they would be larger than the ITTs, but we have no good way of estimating how much larger in the context of this study.

\subsection{Do All Promotional Discounts Backfire? No.}

Table 3 checks whether other promotional discounts backfire as well, by estimating treatment effects of the debit card and auto-debit discount offers on their targeted behaviors during the experiment. The key results here are presented in Row 1-Column 1 and Row 3-

\footnotetext{
${ }^{25}$ Stango and Zinman (2014) also find that consumers do not engineer overdraft reductions by holding larger/buffer balances in their deposit accounts.
} 
Column 2, which, due to our additive specification, identify the effects of offering the debit discount alone on debit card usage, and of offering the auto-pay discount alone on autopayment signup. Debit card usage weakly increases, and auto-pay increases significantly. These effects are each scaled relative to the Overdraft Interest Discount Only message. They are similar for alternative comparisons; if, e.g., we instead estimate effects relative to not getting a debit card discount, the Debit Card Discount Only coefficient for 1/0 debit card usage is 0.0067 ( $\mathrm{SE}=0.0039$ ), and the Debit Card Discount + Overdraft Interest Discount coefficient is 0.0059 ( $\mathrm{SE}=0.0039$ ). Rows 2 and 4 test whether bundling a discount with the Overdraft Interest Discount performs differently, with respect to demand for debit cards and auto-pay, than offering a discount on debit or auto-pay alone. We do not find evidence of differential effects.

In sum, we find no evidence that offering discounts on other bank services backfires with respect to demand for those services, and some evidence that they increase demand as intended.

\subsection{Heterogeneous Effects of Overdraft Messaging?}

Shrouding models, and models of limited attention and salience like Bordalo, Gennaioli, and Shleifer (2015), predict that responses to the advertising of add-ons will vary with how well-informed and/or attentive the consumer is. For example, a well-informed and attentive consumer should respond normally to the overdraft interest discount, and weakly if at all to the overdraft availability reminder.

We construct two proxies for baseline exposure to the overdraft product and then test for whether each proxy mediates our main treatment effects. The first proxy is recent overdraft use prior to the experiment. $18 \%$ of our sample overdrafted at some point during September 2011-August 2012. Appendix Table 2 interacts a prior use indicator with our main treatment variables and shows little evidence of heterogeneous treatment effects (p-values at the bottom of the table). The second proxy is generated by the August $30^{\text {th }}$ message YK sent to half of the sample. This initial overdraft availability reminder may have provided some consumers with information and/or drawn their attention to the add-on. But Appendix Table 3 shows that while the point estimate for the interest discount is more negative for those who first received the August $30^{\text {th }}$ overdraft availability message, the difference is not statistically significant (pvalues at bottom of the table). We caution however that the confidence intervals for the heterogeneity results include both null and economically important point estimates. 
We also estimate quantile treatment effects for the price and availability effects (Figures 4a and 4b). These regressions do not sharply test for the heterogeneity of interest-they are underpowered, and only identify the heterogeneity of interest with the additional assumption that ordinal position in the overdraft distribution is unaffected by treatment-but the idea is that heavier users should be better informed about overdraft costs, and more attuned to overdraft availability, and consequently that both treatment effects should attenuate and even flip sign at high usage. We see hints of this pattern in both Figures 4a and 4b.

\subsection{Do Treatment Effects Persist? Post-Experiment Effects of Overdraft Messaging}

Table 4 re-estimates our main specifications from Table 2 over the post-promotional campaign period, for the two overdraft usage measures for which we have data from JanuaryMay 2013. ${ }^{26}$ (Recall that the most-intensively treated accountholders in our experiment received their last message on December 15, 2012.) We find no statistically significant evidence that treatment effects persist over the five month post-experiment period: the overdraft discount effect is no longer demand-depressing, and the overdraft availability effect is no longer demand-increasing. Figures $3 \mathrm{a}$ and $3 \mathrm{~b}$ plot the two treatment effects and their confidence intervals month-by-month, for our $1 / 0$ measure of overdraft usage, and we see that both treatment effects trend toward zero over the post-campaign period and lose statistical significance about two months post-campaign (between February and March).

All told these results suggest that the behavior changes induced by bank promotions are not "sticky": the changes do not persist long after the promotions stop. This suggests that habit-formation models may not be appropriate for describing overdraft usage. We discuss other implications for theory in Section 5.

\subsection{Other Treatment Variations: Messaging Frequency and Duration}

Appendix Table 4 examines our messaging frequency treatments. The treatments of interest here vary only the frequency of messaging, not message content (Tables 2 and 3) or the amount of time promotional incentives are in place (Appendix Table 5). The results here suggest that more-frequent messaging amplifies the demand-depressing effect of the Overdraft Interest Discount and the demand-increasing effect of the Overdraft Availability message (Table 2).

\footnotetext{
${ }^{26}$ We lack daily data for the post-experiment period and hence cannot calculate our days-with-abalance variable.
} 
The odd columns in Appendix Table 4 estimate the effect of one-shot versus repeated messaging for the September $15^{\text {th }}$ message. In each treatment, the results are null for the oneshot, and strong when the messages are repeated-i.e., more negative for the discount, more positive for availability. Thus the Table 2 results are driven by the repeated messaging, not the one-shot message. Four of the six comparisons between one-shot and repeated messaging coefficients are statistically different from each other, and none of the six p-values is greater than 0.17 . The even columns further break out repeated messaging into more- versus lessfrequent (every 10 days versus every 20 days), and although the point estimates on morefrequent are indeed larger in absolute value in 5 of the 6 comparisons, no difference is statistically significant. The key takeaways from Appendix Table 4 are that one message is not enough to generate an effect, but there are diminishing marginal effects from messaging every 10 vs. 20 days.

Appendix Table 5 examines our other margin of messaging and promotional intensitythe "duration", or length of time over which the bank continued to send messages and offer discounts. Recall that short-duration campaigns lasted until November $15^{\text {th }}$, while longduration campaigns continued until December $15^{\text {th }}$. We find little evidence that duration alone affects demand, either for the overdraft interest discount (row 5 versus row 6), or for the overdraft availability message (row 2 versus row 3), with the lone exception being the availability messaging effect on overdraft average balance (column 6).

Promotional intensity depends on duration and frequency, and the even-numbered columns in Appendix Table 5 shed light on these interactions for the overdraft discount (rows 7-10) and the overdraft availability message (rows 2-4). Comparing, e.g., the most-intense price promotion (row 7: long duration + messages after Sept. 15) to the least-intense promotion (row 10: short duration, no messages after Sept. 15), we find lower demand for the most-intense promotion in all three cases, with p-values on the difference of 0.07, 0.08, and $0.002 .{ }^{27}$ We see a similar pattern of results for overdraft availability marketing, with the point estimate on the most-intense promotion (row 2: long duration + messages after Sept. 15) substantially larger than that on the least-intense promotion (row 4: Sept. 15 message and no subsequent ones), with p-values of $0.07,0.25$, and 0.02 .

\footnotetext{
${ }^{27}$ Also somewhat noteworthy is that the point estimates on one-shot messaging about the overdraft discount suggest weakly normal effects on demand (rows 9 and 10 here in Appendix Table 5, rows 1 and 5 in Appendix Table 4).
} 
All told, we infer that more-intense promotions amplify both the demand-increasing effect of the overdraft availability message and the demand-depressing effect of the overdraft interest discount. This also implies that demand responds more normally—in relative terms at least - to less-intense price promotion.

\section{Mapping from Empirics to Theory}

\subsection{Behavioral Models of Shrouding, Limited Memory, and Limited Attention}

Here we discuss whether and how different theories can make sense of our results. We start with the motivating behavioral models, discussing how they can explain each of our three key results in turn, and then how they can explain the full picture of the results. Because Bordalo et al (2015) (BGS) nests Gabaix and Laibson (2006) (GL) as a special case, at each step of the discussion we start with GL and then highlight where BGS can offer a different interpretation. We conclude by considering alternative explanations: rational inattention, crowd-out of intrinsic motivation, and consumer mistrust of YK.

It will be helpful to keep in mind that a consumer i's expected overdraft costs $f$ are the product of two components (Grubb 2015):

$$
f=\mathrm{E}_{\mathrm{i}}\left(p^{\mathrm{o}} \mid b<0\right) \mathrm{E}_{\mathrm{i}}(b<0),
$$

where $p^{0}$ is the price (30\% or $60 \%$ APR) conditional on the checking account balance $b$ falling below zero. We take expectations of both terms because of uncertainty in checking account balances and the potential for misperception of $p^{0}$. Note that all of the behavioral interpretations below are consistent with $f<f^{*}=$ true overdraft costs, which is why we infer that our results are broadly consistent with an assumption shared by all of our motivating models: consumers tend to systemically underestimate add-on costs.

A GL model neatly explains our first key finding, that overdraft price discounts depress demand. Under GL the overdraft discount messages reduce demand by informing or reminding consumers about one or both overdraft components, thereby getting them to increase their expected overdraft costs. E.g., someone who had been ignoring overdraft prices-assuming that overdrafts are free-- increases $\mathrm{E}_{\mathrm{i}}\left(p^{\mathrm{o}} \mid b<0\right)$, and/or someone who had 
been ignoring the possibility of overdrafts and hence not closely monitoring their balances increases $\mathrm{E}_{\mathrm{i}}(b<0){ }^{28}$

The finding that bundled discounts are especially demand-depressing is outside the GL model but potentially explicable by BGS, which can explicitly model reactions to different types of advertising, through its formalizations of selective memory and salience. Crucially, our overdraft discount results also support the key prediction of equilibrium shrouding models, that firms lack incentives to unshroud. YK unshrouded $p^{0}$ to an extent—an arguably modest extent-- and demand and profits fell.

A GL model can also explain our second key finding, that the overdraft availability message increases demand. The advertising here would operate on those who assumed overdrafting was impossible (and therefore had $f=0$ ) by generating a standard price effect: it makes these clients realize that $p^{0}$ is strictly less than infinite. This price effect in turn must be larger than any effect of drawing attention to nonzero overdraft likelihood. ${ }^{29}$ BGS offers an alternative psychology: consumers tend to neglect available credit as well as cost at baseline, the message makes availability salient, and consumers react to that attribute while continuing to ignore/underweight cost.

Our third key finding, the lack of habit formation, will materialize from a GL model if consumers quickly forget what they inferred from the messages during the advertising campaign. BGS offer another possibility: consumers need not forget per se; rather, it can be the case overdraft attributes are only salient when something-like YK's messages-draws attention to them. In the absence of advertising, consumers do not attend to cost or availability, and behavior quickly reverts to normal: to inattention to the add-on's attributes. Yet another possibility, for the overdraft discount effect dynamics at least, is that consumers underestimate the non-pecuniary costs of overdraft usage, a la Grubb (2015), as well as the pecuniary costs. So the discount messaging induces more vigilant account management to avoid overdrafts in the short-run, but consumers quickly learn that such vigilance is not worth it and revert to their counterfactual usage post-campaign.

\footnotetext{
${ }^{28}$ An effect that works by increasing $\mathrm{E}_{\mathrm{i}}(b<0)$ is also consistent with Grubb (2015).

${ }^{2929}$ The requirement that the price effect swamp the likelihood effect-which would presumably increase $\mathrm{E}(b<0)$ if anything, driving overdraft demand down instead of up-- makes it hard to square the availability message result with Grubb (2015), where consumers accurately perceive $p^{0}$ at baseline.
} 
Putting the three key results together-the perverse effect of overdraft discount ads, the stimulating effect of the overdraft availability ads, and the lack of habit formation-- we suspect that a GL model fits our data so long as there is at least one of two types of heterogeneity among the "myopes" who underestimate overdraft costs at baseline. One type is heterogeneity across myopes in baseline perceptions of overdraft pricing, with myopes underestimating $p^{0}$ in some cases (price result) and overestimating $p^{0}$ in other cases (availability result). The second type does not require heterogeneity across myopes but rather across the mechanism by which messaging changes perceptions of the two overdraft cost components, in the sense that the discount message would have to operate (primarily) by increasing $\mathrm{E}(b<0)$, while the availability message would have to operate by decreasing $\mathrm{E}\left(p^{0}\right.$ | $b<0$ ). BGS requires no such heterogeneity, but does require salience to operate such that consumers focus on costs when price is advertised, and on availability when availability is advertised.

\subsection{Alternative Explanations}

A natural explanation for the overdraft price discount backfiring, particularly in light of Johnson et al (2015), is that consumers view the offer as "too good to be true": they mistrust YK. We agree that it is important to understand the role of (mis)trust in markets for financial services and other products but speculate that mistrust is at most a partial explanation of our results. First, it would not readily explain our other key results on availability and lack of persistence; e.g., it is silent on why availability increases demand, and begs the question of why discount-driven mistrust would dissipate almost immediately after the campaign ends. Second, we wonder why consumers would mistrust this particular offer, but not other deep discounts that prevail in equilibrium, like "free" checking and teaser rates on credit cards. Third, a mistrust channel need not be distinct from the behavioral mechanisms described above; indeed, Johnson et al find that some of their "households expect there to be hidden fees and cumbersome processes that are not compensated by the attractiveness of the offer." Fourth, it is not clear why our consumers would respond by decreasing demand for overdrafts rather than simply ignoring the offer: do consumers assume that hidden costs exceed the value of the discount? Why? Fifth, if YK's clients did think that YK was trying to trick them, we might expect them to reduce their demand for other YK services. Yet we find no evidence of this (Appendix Table 6), and the point estimates of the effect of the overdraft discount on the number of active YK accounts actually go the other way (positive rather than negative). Sixth, there are several institutional differences between our experiment and 
Johnson et al's that make mistrust more important in their context. The offer in Johnson et al was too good to be true in the sense of being government-subsidized. That offer was also made by a mortgage servicer at a time in which the servicing industry was known to be mistreating and scamming customers. ${ }^{30}$

Rational inattention could explain our results, under particular assumptions that strike us as antithetical to these models; e.g., instead of mean-zero but noisy perceptions of costs and credit lines, checking account holders would need to systematically underestimate them. This begs the question of how consumers could rationally underestimate contract terms in equilibrium.

Having said all that, we emphasize that we are not dismissing rational or near-rational explanations for our results. We are merely speculating that behavioral models of limited attention, memory, and shrouding have great potential to explain the full picture.

\section{Conclusion}

Working with a large Turkish bank to test SMS direct marketing promotions to 108,000 existing checking account holders, we find that messages promoting a 50\% discount on the overdraft interest rate reduce overdraft usage. In contrast, messages that merely mention overdraft availability without mentioning price increase usage. Neither change persists long after messages stop, suggesting that induced change in overdrafting is not habit-forming. We also find some evidence that messaging intensity reinforces the main effects of overdraft discount and availability advertising-messaging more about the overdraft discount further reduces demand, while messaging more about overdraft availability further increases demand-and that messages offering discounts on debit card or auto-pay use along with overdraft backfire more than simply offering a discount on overdrafts. But not all discounts backfire; in fact, we find some evidence that debit card and auto-pay discounts increase usage of those features.

Practically speaking, our results suggest that competing on overdraft prices will not capture market share or increase usage, and thus will lower revenue. Although cutting overdraft prices could in principle generate more customer loyalty or reciprocity, the fact that

\footnotetext{
${ }^{30}$ See, e.g., Consumer Financial Protection Bureau (2013) and http://searchenginewatch.com/sew/news/2127978/google-regulators-shut-bing-yahoo-mortgage-scamads .
} 
induced overdraft behavior does not persist suggests these sorts of long-term benefits will not materialize for banks.

More subtly, our results should give pause to third parties seeking to improve overdraft markets with messages (like social marketing campaigns) that draw attention to overdraft costs. To fix ideas, imagine messaging around the theme of "Beware of big overdraft fees!", delivered by an entity that might actually benefit from unshrouding; e.g., a regulator, a firm with social objectives or a product-differentiation strategy, or a personal financial management service. Bordalo, Gennaioli, and Shleifer (2015) formalize the possibility that consumer responses to unshrouding are overreactions rather than optimal responses to new information, and as noted above our results seem consistent with this model. Our results also suggest that unshrouding could be quite costly to sustain, since its effects do not persist. Moreover our results suggest that incumbent suppliers could effectively counter unshrouding campaigns by advertising non-price attributes (like availability/credit lines in our case). Hence we are sympathetic to Heidhues, Koszegi, and Murooka’s conjecture that third-parties, or deviating firms, will be outgunned in a messaging arms race with incumbent add-on suppliers.

Although our results support policymakers' increasing scrutiny of add-on features, pricing, and practices, we once again emphasize that we do not conduct the sort of welfare analysis that ought to motivate and guide policy interventions. One reason we stop short of welfare analysis is that we do not actually have the ability to sharply test existing models of shrouded equilibria, since our experiment considers the existing client base of a single firm rather than competition for customers across firms (Armstrong and Vickers 2012; Gabaix and Laibson 2006; Grubb 2015; Heidhues, Koszegi, and Murooka 2014).

Future work would do well to focus on welfare, although doing so may require far more household-level consumption and expenditure data than is typically available in studies that rely on administrative data alone. Refining our design could also help test across models, for instance by testing promotions that mention price without cutting it, and by mentioning information on price levels as well as or instead of discounts. It would also be useful to examine consumer perceptions of add-on prices and expectations of usage more directly, given their centrality to theoretical assumptions and predictions. 


\section{References}

Agarwal, Sumit, John Driscoll, Xavier Gabaix, and David Laibson. 2013. "Learning in the Credit Card Market.”

Anagol, Santosh, and Hugh Hoikwang Kim. 2012. "The Impact of Shrouded Fees: Evidence from a Natural Experiment in the Indian Mutual Funds Market.” American Economic Review 102 (1): 576-93.

Armstrong, Mark, and John Vickers. 2012. "Consumer Protection and Contingent Charges." Journal of Economic Literature 50 (2): 477-93.

Ater, Itai, and Vardit Landsman. 2013. "Do Customers Learn from Experience? Evidence from Retail Banking.” Management Science 59 (9): 2019-35.

Bakker, Trevor, Nicole Kelly, Jesse Leary, and Eva Nagypal. 2014. “Data Point: Checking Account Overdraft.” Data Point. Consumer Financial Protection Bureau.

Banerjee, Abhijit, Dean Karlan, and Jonathan Zinman. 2015. "Six Randomized Evaluations of Microcredit: Introduction and Further Steps.” American Economic Journal: Applied Economics 7 (1): 1-21.

Bertrand, Marianne, Dean Karlan, Sendhil Mullainathan, Eldar Shafir, and Jonathan Zinman. 2010. "What's Advertising Content Worth? Evidence from a Consumer Credit Marketing Field Experiment.” Quarterly Journal of Economics 125 (1): 263-305.

Bordalo, Pedro, Nicola Gennaioli, and Andrei Shleifer. 2013. "Salience and Consumer Choice.” Journal of Political Economy 121 (5): 803-43. . 2015. "Memory, Attention, and Choice."

Brown, Jennifer, Tanjim Hossain, and John Morgan. 2010. "Shrouded Attributes and Information Suppression: Evidence from the Field.” The Quarterly Journal of Economics 125 (2): 859-76.

Cadena, Ximena, and Antoinette Schoar. 2011. "Remembering to Pay? Reminders vs. Financial Incentives for Loan Payments.” NBER Working Paper 17020, May.

Chetty, Raj, Adam Looney, and Kory Kroft. 2009. "Salience and Taxation: Theory and Evidence.” The American Economic Review 99 (4): 1145-77.

Competition and Markets Authority. 2014. "Personal Current Accounts: Market Study Update.”

Consumer Financial Protection Bureau. 2013. "Supervisory Highlights: Winter 2013."

Dougherty, Carter. 2014. "Banks Face Hit from CFPB on \$30 Billion in Overdraft Fees.” Bloomberg, July 31.

Eliaz, Kfir, and Ran Spiegler. 2011. “Consideration Sets and Competitive Marketing.” Review of Economic Studies 78 (1): 235-62.

Elizondo, Alan, and Enrique Seira. 2014. "Are Information Disclosure Mandates Effective? Evidence from the Credit Card Market."

Ferman, Bruno. Forthcoming. "Reading the Fine Print: Credit Demand and Information Disclosure in Brazil." Management Science

Financial Conduct Authority. 2014. "Consumer Credit Insights: Overdrafts."

Gabaix, Xavier. 2014. “A Sparsity-Based Model of Bounded Rationality.” The Quarterly Journal of Economics 129 (4): 1661-1710.

Gabaix, Xavier, and David Laibson. 2006. "Shrouded Attributes, Consumer Myopia, and Information Suppression in Competitive Markets." Quarterly Journal of Economics 121 (2): 505-40.

General Accounting Office. 2008. "Bank Fees: Federal Banking Regulators Could Better Ensure That Consumers Have Required Disclosure Documents prior to Opening Checking or Savings Accounts.” GAO-08-281. 
Gneezy, Uri, and Aldo Rustichini. 2000. “A Fine Is a Price.” Journal of Legal Studies 29 (1): $1-18$.

Grubb, Michael D. 2009. "Selling to Overconfident Consumers.” The American Economic Review, 1770-1807.

Grubb, Michael D. 2015. "Consumer Inattention and Bill-Shock Regulation.” The Review of Economic Studies 82 (1): 219-57.

Hanna, Rema, Sendhil Mullainathan, and Joshua Schwartzstein. 2014. "Learning Through Noticing: Theory and Experimental Evidence in Farming.” The Quarterly Journal of Economics 129 (3): 1311-53.

Haselhuhn, Michael, Devin Pope, Maurice Schweitzer, and Peter Fishman. 2012. "The Impact of Personal Experience on Behavior: Evidence from Video-Rental Fines.” Management Science 58 (1): 35-51.

Hastings, Justine S., and Jesse M. Shapiro. 2013. "Fungibility and Consumer Choice: Evidence from Commodity Price Shocks.” The Quarterly Journal of Economics 128 (4): 1449-98.

Heidhues, Paul, Botond Koszegi, and Takeshi Murooka. 2014. "Inferior Products and Profitable Deception.”

Hsee, Christopher K. 1998. "Less Is Better: When Low-Value Options Are Valued More Highly than High-Value Options.” Journal of Behavioral Decision Making 11 (2): 107-21.

Johnson, Eric, Stephan Meier, and Olivier Toubia. 2015. "Money Left on the Kitchen Table: Exploring Sluggish Mortgage Refinancing Using Administrative Data, Surveys, and Field Experiments."

Kamenica, Emir. 2012. "Behavioral Economics and Psychology of Incentives.” Annual Review Economics 4 (1): 427-52.

Karlan, Dean, Margaret McConnell, Sendhil Mullainathan, and Jonathan Zinman. Forthcoming. "Getting to the Top of Mind: How Reminders Increase Saving." Management Science

Karlan, Dean, Melanie Morten, and Jonathan Zinman. Forthcoming. “A Personal Touch: Text Messaging for Loan Repayment.” Behavioral Science \& Policy

Kast, Felipe, Stephan Meier, and Dina Pomeranz. 2014. "Under-Savers Anonymous: Evidence on Self-Help Groups and Peer Pressure as a Savings Commitment Device.”

Manoli, Dayanand S., and Nicholas Turner. 2015. "Nudges and Learning: Evidence from Informational Interventions for Low-Income Taxpayers."

Schwartzstein, Joshua. 2014. "Selective Attention and Learning." Journal of the European Economic Association 12 (6): 1423-52.

Spiegler, Ran. 2011. Bounded Rationality and Industrial Organization. Oxford University Press.

Stango, Victor, and Jonathan Zinman. 2009. "What Do Consumers Really Pay on Their Checking and Credit Card Accounts? Explicit, Implicit, and Avoidable Costs." American Economic Review Papers and Proceedings 99 (2): 424-29. . 2014. "Limited and Varying Consumer Attention: Evidence from Shocks to the Salience of Bank Overdraft Fees.” Review of Financial Studies 27 (4): 990-1030.

Zinman, Jonathan. 2014. “Consumer Credit: Too Much or Too Little (or Just Right)?” Journal of Legal Studies 43 (S2 Special Issue on Benefit-Cost Analysis of Financial Regulation): S209-37. 
Figure 1. Experimental Design

Overdraft Availability ( $n=54,000$ ) - "We remind you that, for your immediate cash needs, you have a Flexible Account at Yapi Kredi with [fill]TL limit. Have a nice day"

No Message $(n=54,000)$

Overdraft Availability ( $\mathrm{n}=18,043$ ) - "We remind you that, for your immediate cash needs, you have a Flexible Account at Yapi Kredi with [fill]TL limit. Have a nice day."

Overdraft

Mention

Overdraft

Mention, with

Interest

Discount Account and we will give you back half of the interest that is accrued between now and

[November/December] 15 as WP."

Overdraft Interest Discount + Auto-Pay Discount (n=17,981)- "Authorize automatic bill payments from your account before [November/December] 15, receive up to a maximum of give you back half of your accrued interest as WP." and earn 5\% of your shopping, up to 25TL WP, between now and [November/December] 15.
Overdraft Interest Discount Only, no other discount ( $n=17,977)$ - "Use your Yapi Kredi Flexible 30TL WP. Use your Flexible Account between now and [November/December] 15, and we will

Overdraft Interest Discount + Debit Card Discount $(n=17,995)$ - "Use your Yapi Kredi debit card Use your Flexible Account between now and [November/December] 15, and we will give you back half of your accrued interest as WP."

Auto-Pay Discount Only, no other discount $(n=18,021)$ - "Authorize automatic bill payments from your account before [November/December] 15 and receive up to a maximum of 30TL WP."

Debit Card Discount Only, no other discount $(n=17,983)$ - "Use your Yapi Kredi debit card and earn $5 \%$ of your shopping, up to 25TL WP, between now and [November/Decemberl 15."

\footnotetext{
Frequent Messaging - Msg repeats every 10 Days $(n=35,985)$

Less-frequent Messaging - Msg repeats every 20 Days ( $n=36,052)$

No Additional Messaging after September $15(n=35,963)$
}

Short Duration - Sept 25, 2012 - Nov 15, 2012 ( $n=54,044)$

Long Duration - Sept 25, 2012 - Dec 15, $2012(n=53,956)$

"TL" = Turkish Lira. 1TL = US\$0.56 as of September 2012. "WP"= redeemable reward points. Yapi Kredi $=$ the implementing bank. August 30 and other randomizations are independent. Each randomization is stratified on baseline measures of: gender, place of residence, marital status, and overdraft credit limit, and overdraft balance.
August $30^{\text {th }} 2012$

if sent

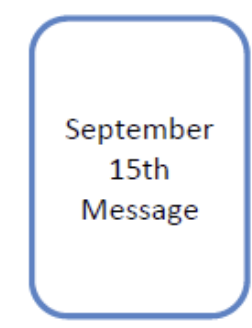

Messages subsequent to Sept 15, if any

Duration of any incentives and any subsequent messages 
Figure 2a: Average FA Amount Used Over Time

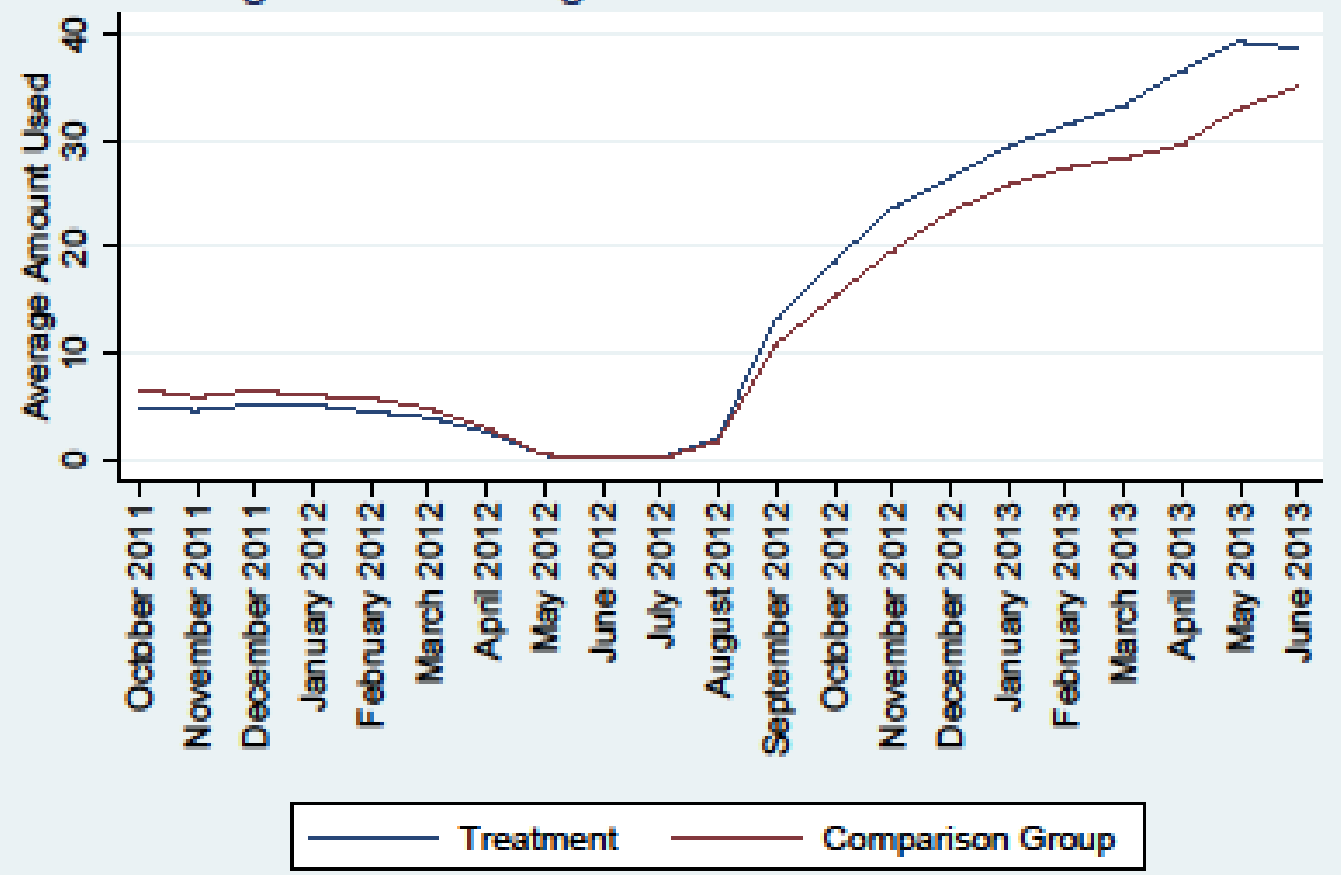

Figure 2b: FA Usage Rates Over Time

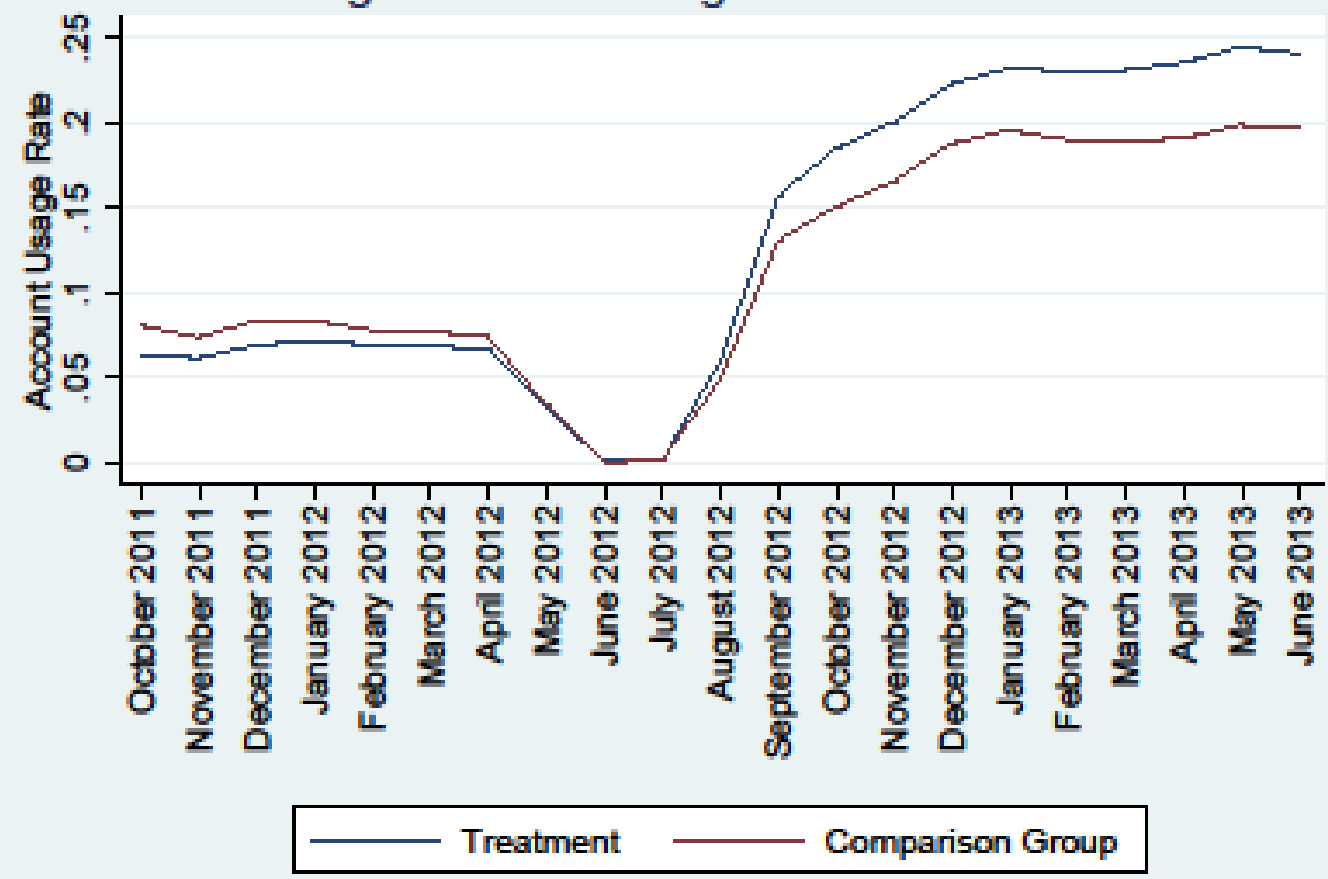


Figure 3a: Effect of Any Overdraft Mention on Overdraft Account Used, Post-Experiment

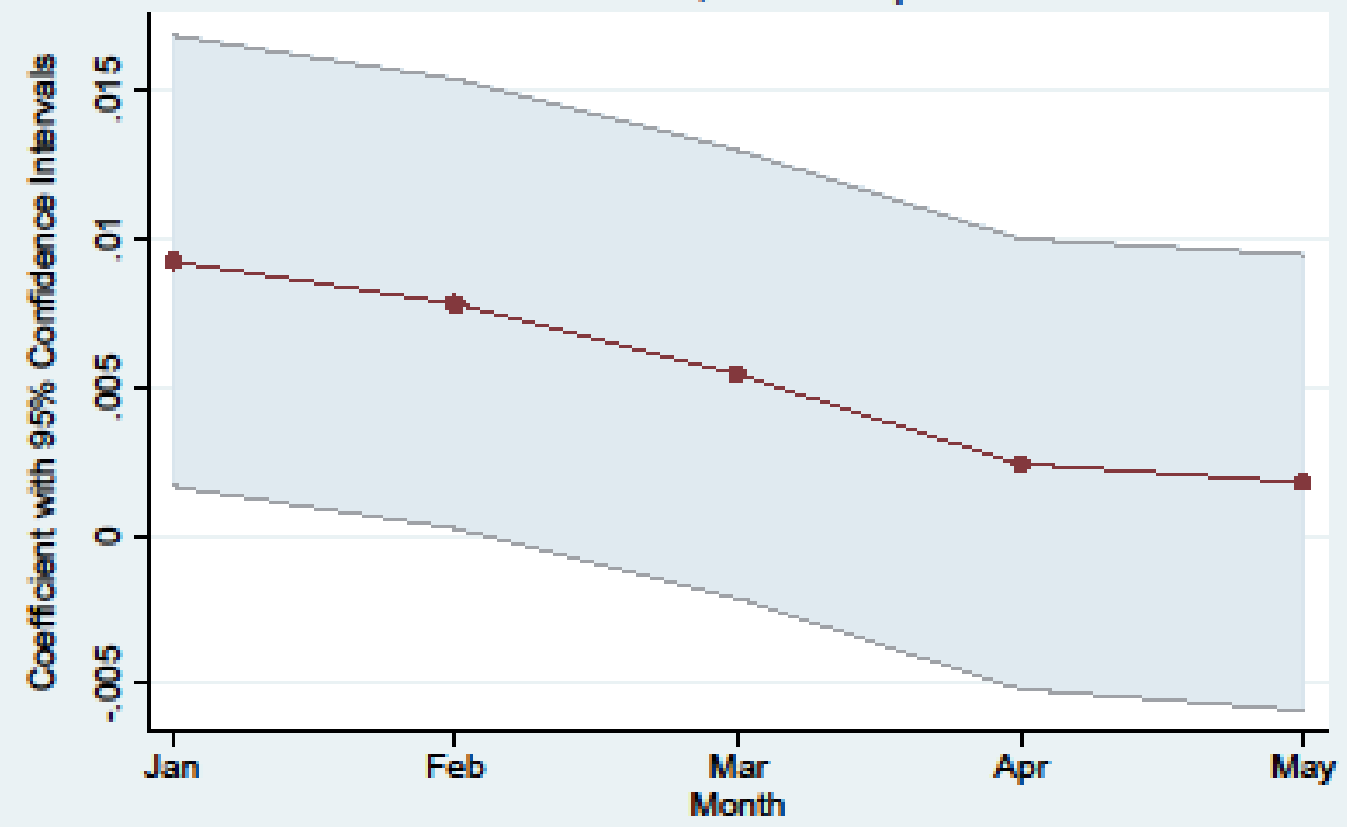

Figure 3b: Effect of Interest Discount on Overdraft Account Used, Post-Experiment

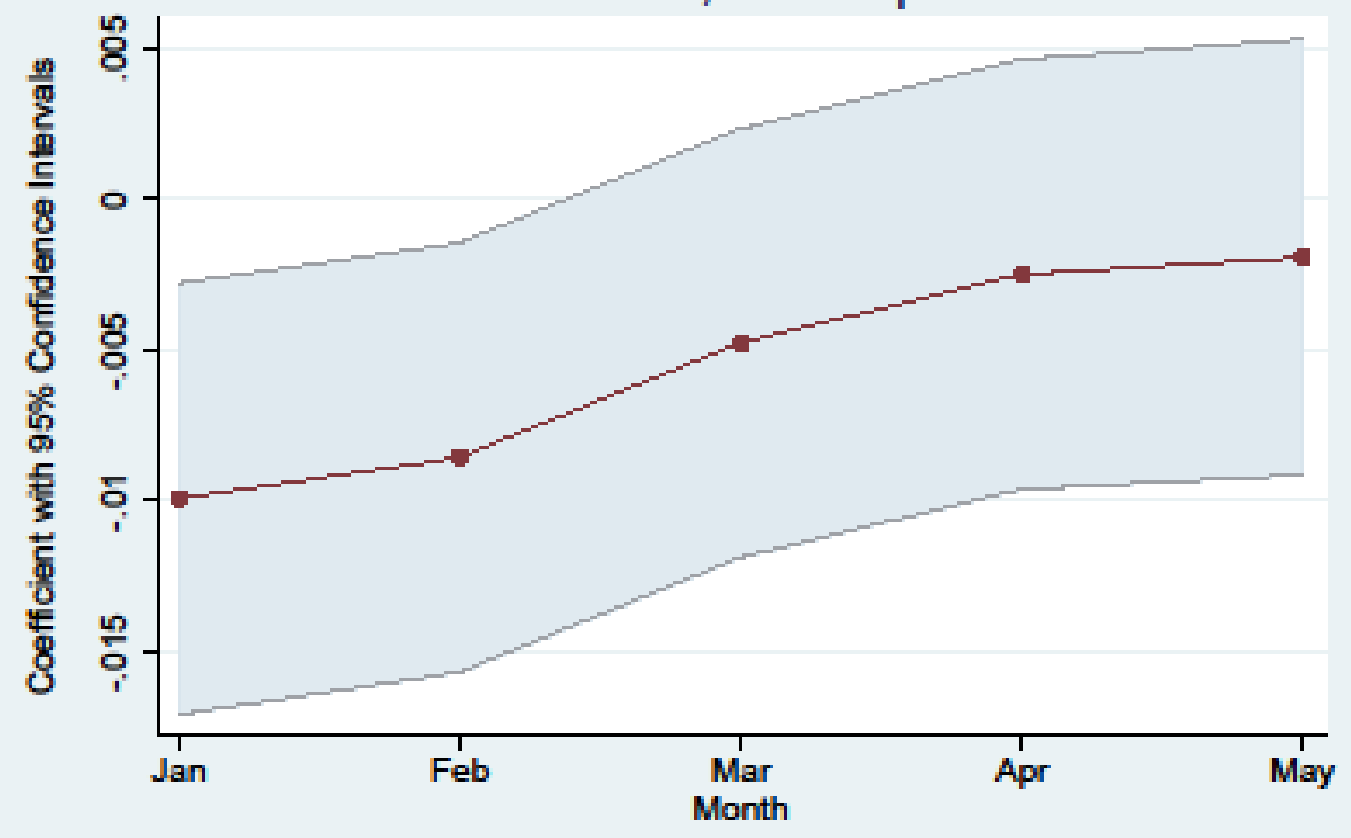


Figure 4a: Distribution of Effect of Overdraft Mention Average Overdraft Balance

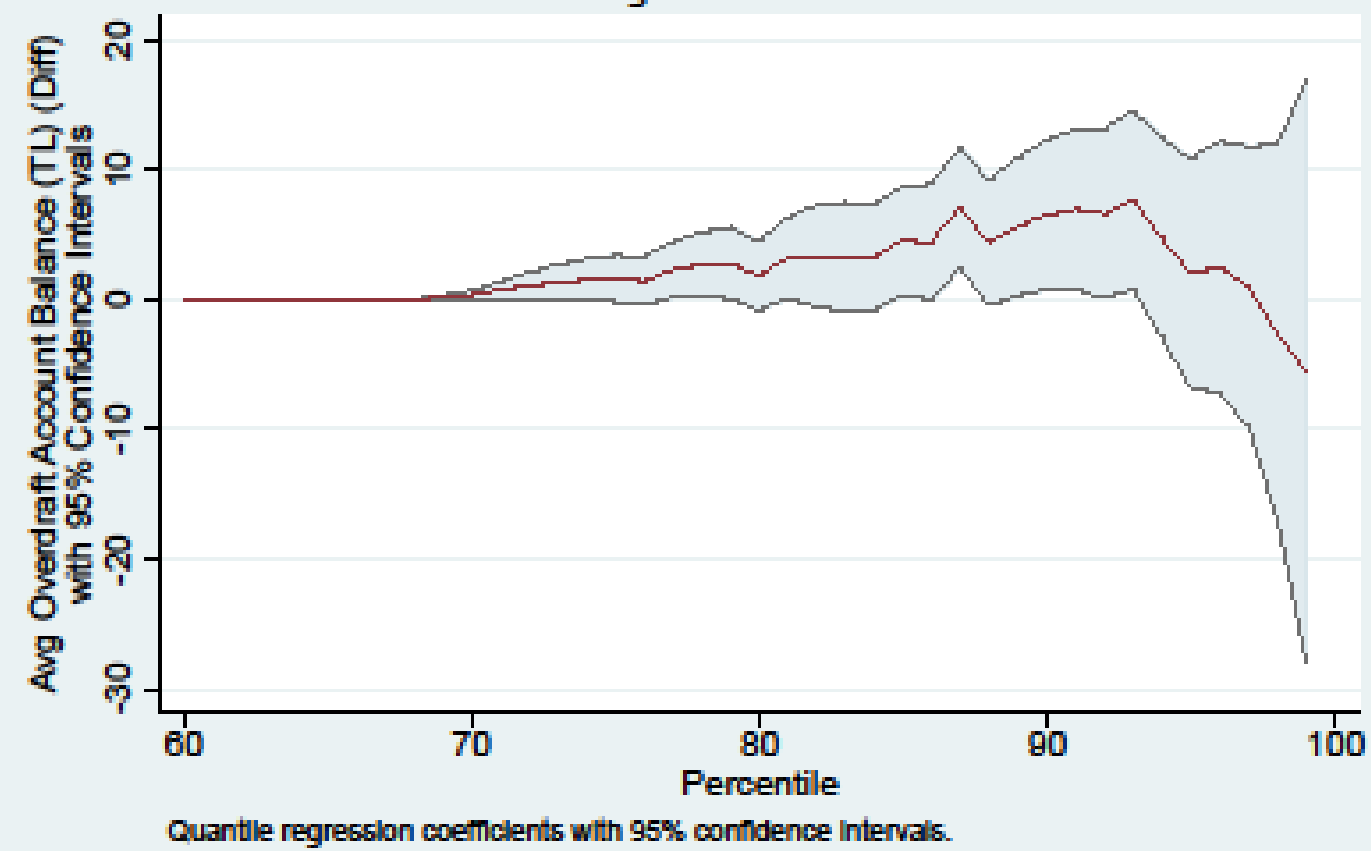

Figure 4b: Distribution of Effect of Interest Incentive, Controlling for Other Overdraft Messages

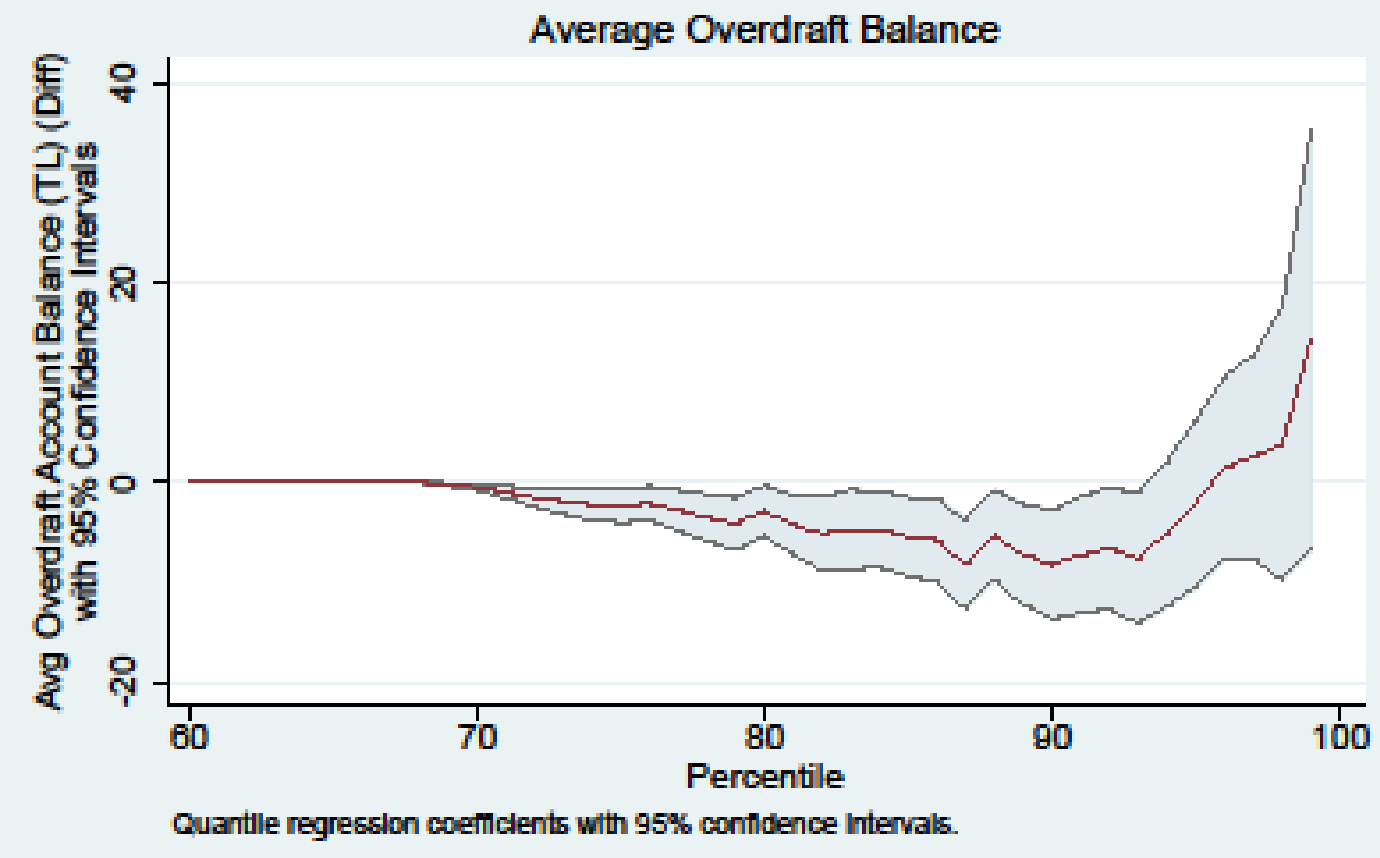




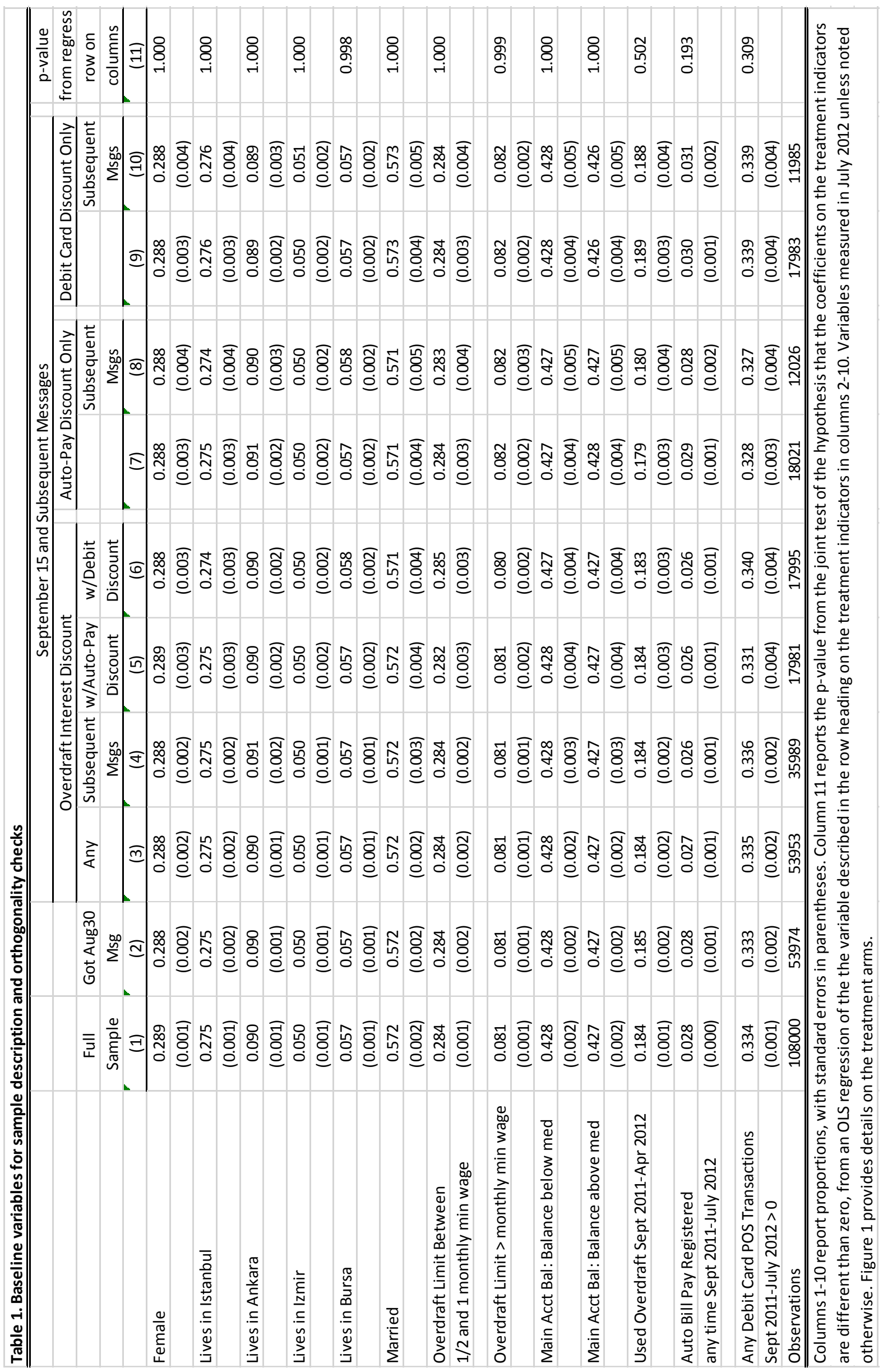


Table 2: Effects of Overdraft Marketing on Overdraft Usage During Experiment (September - December 2012)

\begin{tabular}{|c|c|c|c|c|c|c|}
\hline \multirow[t]{2}{*}{ LHS variable: } & \multicolumn{2}{|c|}{ Overdraft } & \multicolumn{2}{|c|}{ Days with } & \multicolumn{2}{|c|}{ Mean(Overdraft } \\
\hline & \multicolumn{2}{|c|}{ Account Used } & \multicolumn{2}{|c|}{ Overdraft Balance } & \multicolumn{2}{|c|}{ Account Balance) } \\
\hline August 30th Message: & (1) & $(2)$ & (3) & (4) & (5) & (6) \\
\hline \multirow[t]{2}{*}{ (1) Overdraft Availability } & 0.0007 & 0.0007 & $0.0869 * *$ & $0.0869 * *$ & $1.0555^{* *}$ & $1.0554^{* *}$ \\
\hline & $(0.0028)$ & $(0.0028)$ & $(0.0365)$ & $(0.0365)$ & $(0.4701)$ & $(0.4701)$ \\
\hline (2) No Message & Omitted & Omitted & Omitted & Omitted & Omitted & Omitted \\
\hline \multicolumn{7}{|l|}{ September 15 Message: } \\
\hline (3) Overdraft Mention: identifies effect of & $0.0089 * *$ & $0.0089 * *$ & $0.1321^{* *}$ & $0.1321^{* *}$ & 0.9562 & 0.9562 \\
\hline Overdraft Availability message & $(0.0042)$ & $(0.0042)$ & $(0.0553)$ & $(0.0553)$ & $(0.7029)$ & $(0.7029)$ \\
\hline \multirow[t]{2}{*}{ (4) Overdraft Mention, with Interest Discount } & $-0.0124 * * *$ & & $-0.1607^{* * *}$ & & -0.7427 & \\
\hline & $(0.0040)$ & & $(0.0522)$ & & $(0.6718)$ & \\
\hline \multirow[t]{2}{*}{ (5) Overdraft Mention, with Interest Discount only } & & -0.0069 & & -0.0854 & & -0.3382 \\
\hline & & $(0.0049)$ & & $(0.0640)$ & & $(0.8108)$ \\
\hline \multirow[t]{2}{*}{ (6) Overdraft Mention, w/Interest + Auto-Pay Discounts } & & $-0.0137 * * *$ & & $-0.1884 * * *$ & & -1.0909 \\
\hline & & $(0.0049)$ & & $(0.0635)$ & & $(0.8195)$ \\
\hline \multirow[t]{2}{*}{ (7) Overdraft Mention, w/Interest + Debit Card Discounts } & & $-0.0167^{* * *}$ & & $-0.2083^{* * *}$ & & -0.7989 \\
\hline & & $(0.0049)$ & & $(0.0632)$ & & $(0.8397)$ \\
\hline (8) No Overdraft Mention = & Omitted & Omitted & Omitted & Omitted & Omitted & Omitted \\
\hline \multicolumn{7}{|l|}{ Auto-Pay Discount Only or Debit Card Discount Only } \\
\hline Mean(LHS) & 0.3077 & 0.3077 & 2.7676 & 2.7676 & 26.8511 & 26.8511 \\
\hline $\mathrm{SD}(\mathrm{LHS})$ & $(0.46)$ & $(0.46)$ & $(6.05)$ & $(6.05)$ & (77.97) & (77.97) \\
\hline Observations & 108000 & 108000 & 108000 & 108000 & 108000 & 108000 \\
\hline
\end{tabular}

${ }^{* * *} p<=0.01, * * p<=0.05, * p<=0.10$. Each column presents treatment effect estimates from a single OLS regression, with Huber-White standard errors, of the usage measure in the column heading on the experimental variables in the rows. Variables in rows 4-7 identify the additive effect of one or more of the interest discount arms; i.e., they identify the difference in treatment effects between the Overdraft Availability message and the Overdraft Interest Discount. Usage measures cover September 15-December 31, 2012. Account balances are in Turkish Lira, $1 T L=\$ 0.56$ at the start of the experiment. Figure 1 summarizes the experimental design and shows message scripts. Regressions also include controls for randomization strata. Unit of observation is the unit of randomization: a checking account. 


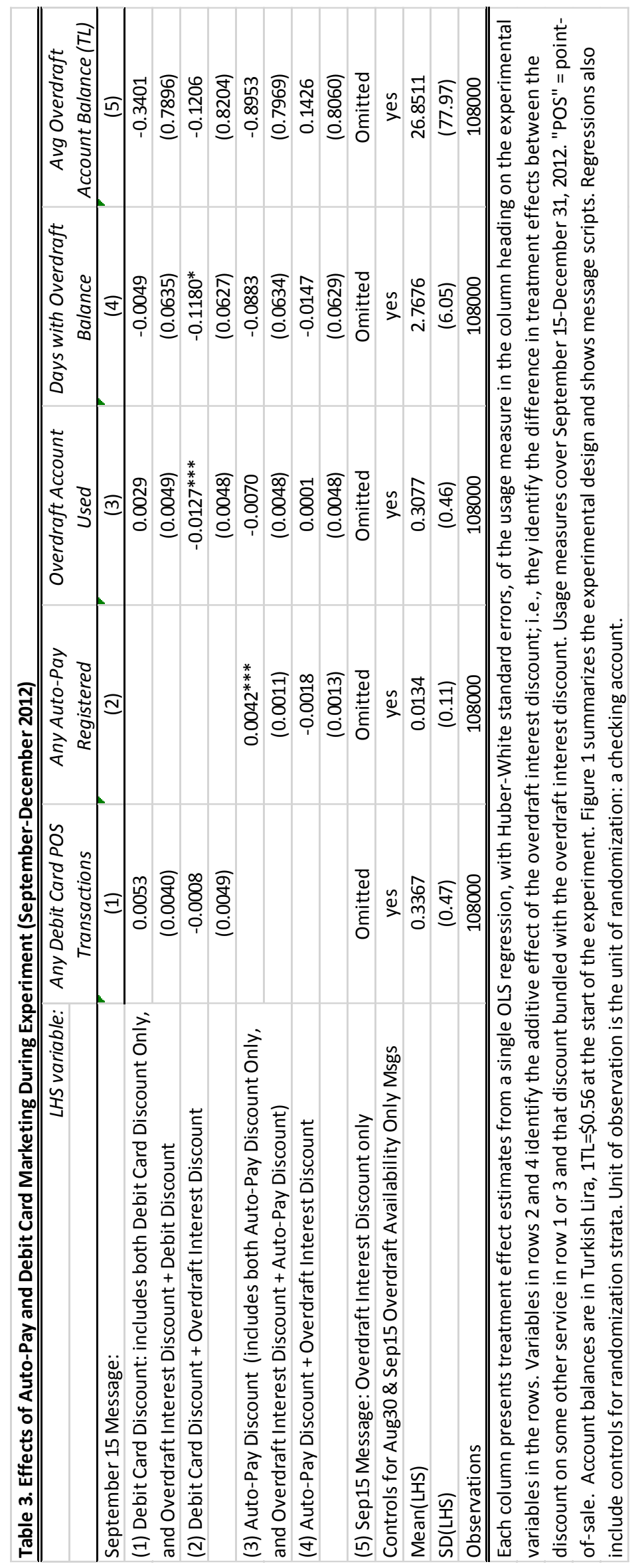


Table 4: Effects of Overdraft Marketing on Overdraft Usage After Experiment (January - May 2013)

\begin{tabular}{|c|c|c|c|c|}
\hline \multirow[t]{2}{*}{ LHS variable: } & \multicolumn{2}{|c|}{ Overdraft } & \multicolumn{2}{|c|}{ Mean(Overdraft } \\
\hline & \multicolumn{2}{|c|}{ Account Used } & \multicolumn{2}{|c|}{ Account Balance) } \\
\hline August 30th Message: & (1) & $(2)$ & (3) & $(4)$ \\
\hline \multirow[t]{2}{*}{ (1) Overdraft Availability } & -0.0004 & -0.0004 & 0.7385 & 0.7383 \\
\hline & $(0.0029)$ & $(0.0029)$ & $(0.6262)$ & $(0.6262)$ \\
\hline (2) No Message & Omitted & Omitted & Omitted & Omitted \\
\hline \multicolumn{5}{|l|}{ September 15 Message: } \\
\hline (3) Overdraft Mention: identifies effect of & 0.0055 & 0.0055 & 0.0320 & 0.0320 \\
\hline Overdraft Availability message & $(0.0044)$ & $(0.0044)$ & $(0.9344)$ & $(0.9344)$ \\
\hline \multirow[t]{2}{*}{ (4) Overdraft Mention, with Interest Discount } & -0.0050 & & 0.1192 & \\
\hline & $(0.0042)$ & & $(0.8916)$ & \\
\hline \multirow[t]{2}{*}{ (5) Overdraft Mention, with Interest Discount only } & & -0.0024 & & 0.8686 \\
\hline & & $(0.0051)$ & & (1.1030) \\
\hline \multirow[t]{2}{*}{ (6) Overdraft Mention, w/Interest + Auto-Pay Discounts } & & -0.0067 & & -0.7063 \\
\hline & & $(0.0051)$ & & $(1.0724)$ \\
\hline \multirow[t]{2}{*}{ (7) Overdraft Mention, w/Interest + Debit Card Discounts } & & -0.0059 & & 0.1954 \\
\hline & & $(0.0051)$ & & $(1.1058)$ \\
\hline (8) No Overdraft Mention = & Omitted & Omitted & Omitted & Omitted \\
\hline \multicolumn{5}{|l|}{ Auto-Pay Discount Only or Debit Card Discount Only } \\
\hline Mean(LHS) & 0.3713 & 0.3713 & 34.0032 & 34.0032 \\
\hline SD(LHS) & $(0.48)$ & $(0.48)$ & $(103.98)$ & $(103.98)$ \\
\hline Observations & 108000 & 108000 & 108000 & 108000 \\
\hline
\end{tabular}

$* * * p<=0.01, * * p<=0.05, * p<=0.10$. Each column presents treatment effect estimates from a single OLS regression, with Huber-White standard errors, of the usage measure in the column heading on the experimental variables in the rows. Variables in rows 4-7 identify the additive effect of one or more of the interest discount arms; i.e., they identify the difference in treatment effects between the Overdraft Availability message and the Overdraft Interest Discount. Usage measures cover January 1May 31, 2012. Account balances are in Turkish Lira, $1 T L=\$ 0.56$ at the start of the experiment. Figure 1 summarizes the experimental design and shows message scripts. Regressions also include controls for randomization strata. Unit of observation is the unit of randomization: a checking account. 
Appendix Table 1. Effects of Marketing on Average Monthly Checking + Savings Balances During Experiment (September-December 2012)

\begin{tabular}{|c|c|c|c|c|c|c|c|c|}
\hline \multirow{2}{*}{ Panel A. Overdraft Marketing } & \multicolumn{2}{|c|}{ Average Balances } & \multicolumn{2}{|c|}{ Top 1\% Winsorized } & \multicolumn{2}{|c|}{ Top 1\% Dropped } & \multicolumn{2}{|c|}{$\log$} \\
\hline & $(1)$ & $(2)$ & (3) & $(4)$ & $(5)$ & $(6)$ & $(7)$ & (8) \\
\hline \multicolumn{9}{|l|}{ August 30th Message: } \\
\hline \multirow[t]{2}{*}{ (1) Overdraft Availability } & -8.8782 & -8.8742 & $-8.5687^{*}$ & $-8.5665^{*}$ & $-7.3419 *$ & $-7.3425^{*}$ & -0.0118 & -0.0118 \\
\hline & $(9.7697)$ & $(9.7695)$ & $(4.9102)$ & $(4.9100)$ & $(3.7965)$ & $(3.7965)$ & $(0.0115)$ & $(0.0115)$ \\
\hline (2) No Message & Omitted & Omitted & Omitted & Omitted & Omitted & Omitted & Omitted & Omitted \\
\hline \multicolumn{9}{|l|}{ September 15 Message: } \\
\hline (3) Overdraft Mention: identifies effect of & -3.5914 & -3.5934 & 2.5982 & 2.5969 & 3.9231 & 3.9228 & -0.0082 & -0.0082 \\
\hline Overdraft Availability message & $(13.9764)$ & $(13.9766)$ & (7.3735) & $(7.3736)$ & $(5.7159)$ & (5.7159) & $(0.0171)$ & $(0.0171)$ \\
\hline \multirow[t]{2}{*}{ (4) Overdraft Mention, with Interest Discount } & 11.4448 & & 3.0329 & & 1.9943 & & 0.0108 & \\
\hline & $(12.2665)$ & & $(6.9651)$ & & $(5.4186)$ & & $(0.0162)$ & \\
\hline \multirow[t]{2}{*}{ (5) Overdraft Mention, with Interest Discount only } & & 24.3365 & & 12.3639 & & 8.0409 & & 0.0237 \\
\hline & & $(15.6249)$ & & $(8.6572)$ & & $(6.7305)$ & & $(0.0199)$ \\
\hline \multirow[t]{2}{*}{ (6) Overdraft Mention, w/Interest + Auto-Pay Discounts } & & 19.7938 & & 7.1275 & & 0.7018 & & 0.0047 \\
\hline & & $(15.7186)$ & & $(8.5911)$ & & $(6.5985)$ & & (0.0199) \\
\hline \multirow[t]{2}{*}{ (7) Overdraft Mention, w/Interest + Debit Card Discounts } & & -9.7688 & & -10.3752 & & -2.7430 & & 0.0042 \\
\hline & & $(14.9912)$ & & $(8.3311)$ & & $(6.5513)$ & & $(0.0197)$ \\
\hline (8) No Overdraft Mention = & Omitted & Omitted & Omitted & Omitted & Omitted & Omitted & Omitted & Omitted \\
\hline \multicolumn{9}{|l|}{ Auto-Pay Discount Only or Debit Card Discount Only } \\
\hline Mean(LHS) & 415.3350 & 415.3350 & 359.4495 & 359.4495 & 305.0098 & 305.0098 & 4.2853 & 4.2853 \\
\hline SD(LHS) & $(1631.25)$ & $(1631.25)$ & $(847.06)$ & (847.06) & $(654.51)$ & $(654.51)$ & $(2.11)$ & $(2.11)$ \\
\hline Observations & 108000 & 108000 & 108000 & 108000 & 106920 & 106920 & 106020 & 106020 \\
\hline \multicolumn{9}{|l|}{ Panel B. Auto-Pay and Debit Card Marketing } \\
\hline \multicolumn{9}{|l|}{ September 15 Message: } \\
\hline \multirow{2}{*}{$\begin{array}{l}\text { (1) Debit Card Discount (includes both Debit Card Discount Only, } \\
\text { and Overdraft Interest Discount + Debit Discount) }\end{array}$} & -13.0974 & & -10.2527 & & $-12.8017^{* *}$ & & -0.0213 & \\
\hline & $(13.5978)$ & & $(7.4184)$ & & $(5.6403)$ & & $(0.0172)$ & \\
\hline \multirow[t]{2}{*}{ (2) Debit Card Discount + Overdraft Interest Discount } & -8.8192 & & -6.2956 & & 6.0471 & & 0.0137 & \\
\hline & $(15.5592)$ & & $(8.3217)$ & & $(6.4248)$ & & $(0.0198)$ & \\
\hline \multirow{2}{*}{$\begin{array}{l}\text { (3) Auto-Pay Discount (includes both Auto-Pay Discount Only, } \\
\text { and Overdraft Interest Discount + Auto-Pay Discount) }\end{array}$} & -4.0234 & & -7.2920 & & -3.0861 & & 0.0140 & \\
\hline & $(17.0081)$ & & $(7.3615)$ & & $(5.7486)$ & & $(0.0172)$ & \\
\hline \multirow[t]{2}{*}{ (4) Auto-Pay Discount + Overdraft Interest Discount } & 11.6737 & & 8.2507 & & -0.2214 & & -0.0211 & \\
\hline & $(19.2085)$ & & $(8.5362)$ & & (6.5709) & & $(0.0199)$ & \\
\hline (5) Overdraft Interest Discount only & Omitted & & Omitted & & Omitted & & Omitted & \\
\hline Controls for Aug30 \& Sep 15 Overdraft Availability Only Messages & yes & & yes & & yes & & yes & \\
\hline Mean(LHS) & 415.3350 & & 359.4495 & & 305.0098 & & 4.2853 & \\
\hline SD(LHS) & $(1631.25)$ & & (847.06) & & (654.51) & & (2.11) & \\
\hline Observations & 108000 & & 108000 & & 106920 & & 106020 & \\
\hline \multicolumn{9}{|c|}{$\begin{array}{l}* * p<=0.01,{ }^{* *} p<=0.05,{ }^{*} p<=0.10 \text {. Each column-panel presents treatment effect estimates from a single OLS regression, with Huber-White standard errors, } \\
\text { of the average balances measure in the column heading on the experimental variables in the rows. Variables in Panel A rows } 4-7 \text { identify the additive } \\
\text { effect of one or more of the interest discount arms; i.e., they identify the difference in treatment effects between the Overdraft Availability message and } \\
\text { the Overdraft Interest Discount. Variables in Panel B rows } 2 \text { and } 4 \text { identify the additive effect of the overdraft interest discount; i.e., they identify the } \\
\text { difference in treatment effects between the discount on some other service in row } 1 \text { or } 3 \text { and that discount bundled with the overdraft interest discount. } \\
\text { Balance measures cover September } 15-D e c e m b e r ~ 31,2012 \text {. Account balances are in Turkish Lira, } 1 \mathrm{TL}=\$ 0.56 \text { at the start of the experiment. Figure } 1 \\
\text { summarizes the experimental design and shows message scripts. Regressions also include controls for randomization strata. Unit of observation is the unit } \\
\text { of randomization: a checking account. }\end{array}$} \\
\hline
\end{tabular}




\begin{tabular}{|c|c|c|c|c|c|c|}
\hline \multicolumn{7}{|l|}{ Appendix Table 2. Heterogenous Treatment Effects by Prior Use? } \\
\hline LHS variable: & \multicolumn{2}{|c|}{ Overdraft } & \multicolumn{2}{|c|}{ Days with } & \multicolumn{2}{|c|}{ Mean(Overdraft } \\
\hline \multirow[t]{2}{*}{ Measured during experiment: over September 15-December 31, 2012} & \multicolumn{2}{|c|}{ Account Used } & \multicolumn{2}{|c|}{ Overdraft Balance } & \multicolumn{2}{|c|}{ Account Balance) } \\
\hline & $(1)$ & $(2)$ & $(3)$ & (4) & $(5)$ & $(6)$ \\
\hline \multirow[t]{2}{*}{ (1) Prior Overdraft Use } & $0.3201 * * *$ & $0.3201 * * *$ & $4.0976 * * *$ & $4.0976 * * *$ & $41.6837^{* * *}$ & $41.6835^{* * *}$ \\
\hline & $(0.0067)$ & $(0.0067)$ & $(0.1093)$ & $(0.1093)$ & $(1.5148)$ & $(1.5148)$ \\
\hline No Overdraft Use September 2011-April 2012 & Omitted & Omitted & Omitted & Omitted & Omitted & Omitted \\
\hline \multicolumn{7}{|l|}{ September 15th Message: } \\
\hline \multirow[t]{2}{*}{ (2) Overdraft Mention * Prior Overdraft Use } & $0.0193^{*}$ & 0.0193* & 0.2546 & 0.2546 & 0.5915 & 0.5920 \\
\hline & $(0.0107)$ & $(0.0107)$ & $(0.1807)$ & $(0.1807)$ & $(2.5326)$ & $(2.5326)$ \\
\hline \multirow[t]{2}{*}{ (3) Overdraft Mention * No Prior Overdraft Use } & 0.0055 & 0.0055 & $0.0912^{*}$ & $0.0912^{*}$ & 0.8841 & 0.8843 \\
\hline & $(0.0044)$ & $(0.0044)$ & $(0.0521)$ & $(0.0521)$ & $(0.6385)$ & $(0.6385)$ \\
\hline \multirow[t]{2}{*}{ (4) Overdraft Mention, with Interest Discount * Prior Overdraft Use } & $-0.0205^{* *}$ & & -0.2640 & & 0.4073 & \\
\hline & $(0.0101)$ & & $(0.1703)$ & & $(2.3965)$ & \\
\hline \multirow[t]{2}{*}{ (5) Overdraft Mention, with Interest Discount * No Prior Overdraft Use } & $-0.0094^{* *}$ & & $-0.1223^{* *}$ & & -0.8171 & \\
\hline & $(0.0041)$ & & $(0.0492)$ & & $(0.6130)$ & \\
\hline \multirow[t]{2}{*}{ (6) Overdraft Interest Discount, No Other Discount * Prior Overdraft Use } & & -0.0176 & & -0.1611 & & 1.1800 \\
\hline & & $(0.0124)$ & & $(0.2097)$ & & $(2.9235)$ \\
\hline \multirow[t]{2}{*}{ (7) Overdraft Interest Discount, No Other Discount * No Prior Overdraft Use } & & -0.0036 & & -0.0559 & & -0.5237 \\
\hline & & $(0.0051)$ & & $(0.0603)$ & & $(0.7335)$ \\
\hline \multirow[t]{2}{*}{ (8) Overdraft Interest Discount + Auto-Pay Discount * Prior Overdraft Use } & & -0.0204 & & $-0.3532^{*}$ & & -1.6837 \\
\hline & & $(0.0124)$ & & $(0.2093)$ & & $(2.9142)$ \\
\hline \multirow[t]{2}{*}{ (9) Overdraft Interest Discount + Auto-Pay Discount * No Prior Overdraft Use } & & $-0.0109 * *$ & & $-0.1362 * *$ & & -0.7935 \\
\hline & & $(0.0050)$ & & $(0.0598)$ & & $(0.7550)$ \\
\hline \multirow[t]{2}{*}{ (10) Overdraft Interest Discount + Debit Card Discount * Prior Overdraft Use } & & $-0.0236^{*}$ & & -0.2784 & & 1.7192 \\
\hline & & $(0.0124)$ & & $(0.2093)$ & & $(3.0806)$ \\
\hline \multirow[t]{2}{*}{ (11) Overdraft Interest Discount + Debit Card Discount * No Prior Overdraft Use } & & $-0.0137^{* * *}$ & & $-0.1745^{* * *}$ & & -1.1335 \\
\hline & & $(0.0050)$ & & $(0.0592)$ & & $(0.7528)$ \\
\hline No Overdraft Mention = Auto-Pay Discount Only or Debit Card Discount Only & Omitted & Omitted & Omitted & Omitted & Omitted & Omitted \\
\hline p-value on F-test of equality between rows ( 2 ) and ( 3 ) & 0.2348 & 0.2348 & 0.3852 & 0.3851 & 0.9108 & 0.9109 \\
\hline$p$-value on F-test of equality between rows (4) and (5) & 0.3068 & & 0.4239 & & 0.6203 & \\
\hline$p$-value on F-test of equality between rows (6) and (7) & & 0.2952 & & 0.6297 & & 0.5716 \\
\hline$p$-value on F-test of equality between rows ( 8 ) and (9) & & 0.4793 & & 0.3190 & & 0.7675 \\
\hline p-value on F-test of equality between rows (10) and (11) & & 0.4578 & & 0.6330 & & 0.3678 \\
\hline Mean(LHS) & 0.3077 & 0.3077 & 2.7676 & 2.7676 & 26.8511 & 26.8511 \\
\hline $\mathrm{SD}(\mathrm{LHS})$ & $(0.46)$ & $(0.46)$ & $(6.05)$ & $(6.05)$ & $(77.97)$ & (77.97) \\
\hline Observations & 108000 & 108000 & 108000 & 108000 & 108000 & 108000 \\
\hline \multicolumn{7}{|c|}{$\begin{array}{l}* * * p<=0.01,{ }^{* *} p<=0.05,{ }^{*} p<=0.10 \text {. Each column presents treatment effect estimates from a single OLS regression, with Huber-White standard errors, of } \\
\text { the usage measure in the column heading on the experimental variables in the rows. Variables in rows } 4 \text { - } 11 \text { identify the additive effect of one or more of } \\
\text { the interest discount arms; i.e., they identify the difference in treatment effects between the Overdraft Availability message and the Overdraft Interest } \\
\text { Discount. Overdraft usage measures cover September } 15 \text {-December } 31,2012 \text {, except for prior use, which is measured } 1 / 0 \text { pre-experiment, over } \\
\text { September 2011-April 2012. Account balances are in Turkish Lira, } 1 T L=\$ 0.56 \text { at the start of the experiment. Figure } 1 \text { summarizes the experimental design } \\
\text { and shows message scripts. Regressions also include controls for randomization strata. Unit of observation is the unit of randomization: a checking } \\
\text { account. }\end{array}$} \\
\hline
\end{tabular}


Appendix Table 3. Does the August 30 Message Mediate Treatment Effects of Later Messages?

\begin{tabular}{|c|c|c|c|c|c|c|}
\hline \multirow{2}{*}{$\begin{array}{rr}\text { Leasured during experiment: over September 15-December 31, } 2012 \\
\text { Liable: }\end{array}$} & \multicolumn{2}{|c|}{ Overdraft } & \multicolumn{2}{|c|}{ Days with } & \multicolumn{2}{|c|}{ Mean(Overdraft } \\
\hline & \multicolumn{2}{|c|}{ Account Used } & \multicolumn{2}{|c|}{ Overdraft Balance } & \multicolumn{2}{|c|}{ Account Balance) } \\
\hline August 30th Message: & $(1)$ & $(2)$ & $(3)$ & (4) & $(5)$ & $(6)$ \\
\hline \multirow[t]{2}{*}{ (1) Overdraft Availability } & -0.0001 & -0.0001 & 0.0477 & 0.0476 & 1.1445 & 1.1444 \\
\hline & $(0.0049)$ & $(0.0049)$ & $(0.0631)$ & $(0.0631)$ & $(0.7875)$ & $(0.7875)$ \\
\hline No message & Omitted & Omitted & Omitted & Omitted & Omitted & Omitted \\
\hline \multicolumn{7}{|l|}{ September 15 Message: } \\
\hline \multirow[t]{2}{*}{ (2) Overdraft Mention with Aug $30 \mathrm{Msg}$} & $0.0114^{*}$ & $0.0114^{*}$ & $0.2021 * *$ & $0.2021^{* *}$ & 0.7911 & 0.7912 \\
\hline & $(0.0060)$ & $(0.0060)$ & $(0.0797)$ & $(0.0797)$ & $(1.0046)$ & (1.0046) \\
\hline \multirow[t]{2}{*}{ (3) Overdraft Mention without Aug $30 \mathrm{Msg}$} & 0.0063 & 0.0063 & 0.0622 & 0.0622 & 1.1209 & 1.1212 \\
\hline & $(0.0060)$ & $(0.0060)$ & $(0.0767)$ & $(0.0767)$ & $(0.9814)$ & $(0.9815)$ \\
\hline \multirow[t]{2}{*}{ (4) Overdraft Mention, with Interest Discount, with Aug 30 Msg } & $-0.0151 * * *$ & & $-0.2149 * * *$ & & -0.6116 & \\
\hline & $(0.0056)$ & & $(0.0755)$ & & $(0.9576)$ & \\
\hline \multirow[t]{2}{*}{ (5) Overdraft Mention, with Interest Discount, w/o Aug 30 Msg } & $-0.0098 *$ & & -0.1067 & & -0.8735 & \\
\hline & $(0.0056)$ & & $(0.0722)$ & & $(0.9420)$ & \\
\hline \multirow[t]{2}{*}{ (6) Overdraft Interest Discount, No Other Discount, with Aug $30 \mathrm{Msg}$} & & -0.0082 & & $-0.1819 * *$ & & -0.9928 \\
\hline & & $(0.0069)$ & & $(0.0916)$ & & $(1.1290)$ \\
\hline \multirow[t]{2}{*}{ (7) Overdraft Interest Discount, No Other Discount, w/o Aug $30 \mathrm{Msg}$} & & -0.0056 & & 0.0109 & & 0.3160 \\
\hline & & (0.0069) & & $(0.0895)$ & & (1.1630) \\
\hline \multirow[t]{2}{*}{ (8) Overdraft Interest Discount + Auto-Pay Discount, w/Aug 30 Msg } & & $-0.0135^{*}$ & & $-0.1894 * *$ & & 0.0209 \\
\hline & & $(0.0069)$ & & $(0.0922)$ & & (1.1848) \\
\hline \multirow[t]{2}{*}{ (9) Overdraft Interest Discount + Auto-Pay Discount, w/o Aug 30 Msg } & & $-0.0139 * *$ & & $-0.1875^{* *}$ & & $-2.2005^{*}$ \\
\hline & & $(0.0069)$ & & $(0.0875)$ & & $(1.1330)$ \\
\hline \multirow[t]{2}{*}{ (10) Overdraft Interest Discount + Debit Card Discount, with Aug 30 Msg } & & $-0.0236 * * *$ & & $-0.2734^{* * *}$ & & -0.8622 \\
\hline & & $(0.0069)$ & & $(0.0911)$ & & $(1.2162)$ \\
\hline \multirow[t]{2}{*}{ (11) Overdraft Interest Discount + Debit Card Discount, w/o Aug 30 Msg } & & -0.0098 & & -0.1434 & & -0.7351 \\
\hline & & $(0.0069)$ & & $(0.0877)$ & & $(1.1541)$ \\
\hline No Overdraft Mention = Auto-Pay Discount Only or Debit Card Discount Only & Omitted & Omitted & Omitted & Omitted & Omitted & Omitted \\
\hline$p$-value on F-test of equality between rows (2) and ( 3 ) & 0.5475 & 0.5477 & 0.2058 & 0.2058 & 0.8142 & 0.8140 \\
\hline$p$-value on F-test of equality between rows (4) and (5) & 0.5031 & & 0.2999 & & 0.8454 & \\
\hline p-value on F-test of equality between rows (6) and (7) & & 0.7870 & & 0.1323 & & 0.4192 \\
\hline$p$-value on F-test of equality between rows ( 8 ) and (9) & & 0.9644 & & 0.9875 & & 0.1755 \\
\hline p-value on F-test of equality between rows (10) and (11) & & 0.1556 & & 0.3038 & & 0.9395 \\
\hline Mean(LHS) & 0.3077 & 0.3077 & 2.7676 & 2.7676 & 26.8511 & 26.8511 \\
\hline $\mathrm{SD}(\mathrm{LHS})$ & $(0.46)$ & $(0.46)$ & $(6.05)$ & $(6.05)$ & $(77.97)$ & $(77.97)$ \\
\hline Observations & 108000 & 108000 & 108000 & 108000 & 108000 & 108000 \\
\hline
\end{tabular}

*** $p<=0.01,{ }^{* *} p<=0.05,{ }^{*} p<=0.10$. Each column presents treatment effect estimates from a single OLS regression, with Huber-White standard errors, of the usage measure in the column heading on the experimental variables in the rows. Variables in rows 4-11 identify the additive effect of one or more of the interest discount arms; i.e., they identify the difference in treatment effects between the Overdraft Availability message and the Overdraft Interest Discount. Overdraft usage measures cover September 15-December 31, 2012. Account balances are in Turkish Lira, $1 T L=\$ 0.56$ at the start of the experiment. Figure 1 summarizes the experimental design and shows message scripts. Regressions also include controls for randomization strata. Unit of observation is the unit of randomization: a checking account. 
Appendix Table 4. Effects of Overdraft Marketing Frequency on Overdraft Usage During Experiment (September - December 2012)

\begin{tabular}{|c|c|c|c|c|c|c|}
\hline \multirow[t]{2}{*}{ LHS variable: } & \multicolumn{2}{|c|}{ Overdraft } & \multicolumn{2}{|c|}{ Days with } & \multicolumn{2}{|c|}{ Mean(Overdraft } \\
\hline & \multicolumn{2}{|c|}{ Account Used } & \multicolumn{2}{|c|}{ Overdraft Balance } & \multicolumn{2}{|c|}{ Account Balance) } \\
\hline September 15 Message: & (1) & $(2)$ & (3) & $(4)$ & $(5)$ & $(6)$ \\
\hline \multirow[t]{2}{*}{ (1) Overdraft Mention No Subsequent Messages } & 0.0003 & 0.0003 & 0.0429 & 0.0429 & -0.3108 & -0.3108 \\
\hline & $(0.0064)$ & $(0.0064)$ & $(0.0835)$ & $(0.0835)$ & $(1.0420)$ & $(1.0420)$ \\
\hline \multirow[t]{2}{*}{ (2) Overdraft Mention + Subsequent Messages } & $0.0132 * * *$ & & $0.1765^{* * *}$ & & $1.5872^{*}$ & \\
\hline & $(0.0049)$ & & $(0.0644)$ & & $(0.8283)$ & \\
\hline \multirow[t]{2}{*}{ (3) Overdraft Mention + Frequent Messages } & & $0.0136^{* *}$ & & $0.2119 * *$ & & 1.4980 \\
\hline & & $(0.0065)$ & & $(0.0854)$ & & $(1.0996)$ \\
\hline \multirow[t]{2}{*}{ (4) Overdraft Mention + Infrequent Messages } & & $0.0127^{* *}$ & & $0.1411 *$ & & 1.6763 \\
\hline & & $(0.0065)$ & & $(0.0855)$ & & $(1.1017)$ \\
\hline \multirow[t]{2}{*}{ (5) Overdraft Mention, with Interest Discount, No Subsequent Messages } & -0.0017 & -0.0017 & 0.0386 & 0.0385 & 1.8416 & 1.8416 \\
\hline & $(0.0069)$ & $(0.0069)$ & $(0.0898)$ & $(0.0898)$ & $(1.1400)$ & $(1.1400)$ \\
\hline \multirow[t]{2}{*}{ (6) Overdraft Mention, with Interest Discount + Subsequent Messages } & $-0.0178 * * *$ & & $-0.2602 * * *$ & & $-2.0319 * *$ & \\
\hline & $(0.0049)$ & & $(0.0642)$ & & $(0.8315)$ & \\
\hline \multirow[t]{2}{*}{ (7) Overdraft Mention, with Interest Discount + Frequent Messages } & & $-0.0207 * * *$ & & $-0.3368 * * *$ & & $-2.0617^{*}$ \\
\hline & & $(0.0069)$ & & $(0.0906)$ & & $(1.1763)$ \\
\hline \multirow[t]{2}{*}{ (8) Overdraft Mention, with Interest Discount + Infrequent Messages } & & $-0.0149 * *$ & & $-0.1836 * *$ & & $-2.0021 *$ \\
\hline & & $(0.0069)$ & & $(0.0909)$ & & $(1.1706)$ \\
\hline (9) No Overdraft Mention = Auto-Pay Discount Only or Debit Card Discount Only & Omitted & Omitted & Omitted & Omitted & Omitted & Omitted \\
\hline Mean(LHS) & 0.3077 & 0.3077 & 2.7676 & 2.7676 & 26.8511 & 26.8511 \\
\hline $\mathrm{SD}(\mathrm{LHS})$ & $(0.46)$ & $(0.46)$ & $(6.05)$ & $(6.05)$ & (77.97) & (77.97) \\
\hline Observations & 108000 & 108000 & 108000 & 108000 & 108000 & 108000 \\
\hline
\end{tabular}

*** $p<=0.01, * * p<=0.05, * p<=0.10$. Each column presents treatment effect estimates from a single OLS regression, with Huber-White standard errors, of the usage measure in the column heading on the experimental variables in the rows. Variables in rows 5-8 identify the additive effect of one or more of the interest discount arms; i.e., they identify the difference in treatment effects between the Overdraft Availability message and the Overdraft Interest Discount. Usage measures cover September 15-December 31, 2012. Account balances are in Turkish Lira, 1 TL=\$0.56 at the start of the experiment. Figure 1 summarizes the experimental design and shows message scripts. Regressions also include controls for randomization strata. Unit of observation is the unit of randomization: a checking account. 


\begin{tabular}{|c|c|c|c|c|c|c|}
\hline \multirow[t]{2}{*}{ LHS variable: } & \multicolumn{2}{|c|}{ Overdraft } & \multicolumn{2}{|c|}{ Days with } & \multicolumn{2}{|c|}{ Mean(Overdraft } \\
\hline & \multicolumn{2}{|c|}{ Account Used } & \multicolumn{2}{|c|}{ Overdraft Balance } & \multicolumn{2}{|c|}{ Account Balance) } \\
\hline September 15 Message: & (1) & $(2)$ & (3) & $(4)$ & $(5)$ & $(6)$ \\
\hline \multirow[t]{2}{*}{ (1) Overdraft Mention: identifies effect of Overdraft Availability Message } & $0.0089^{* *}$ & & $0.1320^{* *}$ & & 0.9556 & \\
\hline & $(0.0042)$ & & $(0.0553)$ & & (0.7029) & \\
\hline \multirow[t]{2}{*}{ (2) Overdraft Mention, long duration, with Subsequent Messages } & & $0.0154^{* *}$ & & $0.1718^{* *}$ & & $3.1076 * * *$ \\
\hline & & $(0.0065)$ & & $(0.0857)$ & & $(1.1831)$ \\
\hline \multirow[t]{2}{*}{ (3) Overdraft Mention, short duration, with Subsequent Messages } & & 0.0109* & & $0.1811^{* *}$ & & 0.0711 \\
\hline & & $(0.0065)$ & & $(0.0853)$ & & $(1.0163)$ \\
\hline \multirow[t]{2}{*}{ (4) Overdraft Mention No Subsequent Messages } & & 0.0003 & & 0.0429 & & -0.3108 \\
\hline & & $(0.0064)$ & & $(0.0835)$ & & $(1.0420)$ \\
\hline \multirow[t]{2}{*}{ (5) Overdraft Mention, with Interest Discount, long duration } & $-0.0134 * * *$ & & $-0.1467^{* *}$ & & -1.0662 & \\
\hline & $(0.0044)$ & & $(0.0583)$ & & $(0.7510)$ & \\
\hline \multirow[t]{2}{*}{ (6) Overdraft Mention, with Interest Discount, short duration } & $-0.0114^{* *}$ & & $-0.1747^{* * *}$ & & -0.4189 & \\
\hline & $(0.0044)$ & & $(0.0580)$ & & $(0.7516)$ & \\
\hline \multirow[t]{2}{*}{ (7) Overdraft Mention, with Interest Discount, long duration, with Subsequent Messages } & & $-0.0227^{* * *}$ & & $-0.2671^{* * *}$ & & $-4.2866 * * *$ \\
\hline & & $(0.0069)$ & & $(0.0910)$ & & $(1.2475)$ \\
\hline \multirow[t]{2}{*}{ (8) Overdraft Mention, with Interest Discount, short duration, with Subsequent Messages } & & $-0.0129 *$ & & $-0.2533 * * *$ & & 0.2155 \\
\hline & & $(0.0069)$ & & $(0.0905)$ & & (1.0995) \\
\hline \multirow[t]{2}{*}{ (9) Overdraft Mention, with Interest Discount, long duration, w/o Subsequent Messages } & & 0.0006 & & 0.1033 & & $2.3327^{*}$ \\
\hline & & $(0.0077)$ & & $(0.1014)$ & & $(1.3053)$ \\
\hline \multirow[t]{2}{*}{ (10) Overdraft Mention, with Interest Discount, short duration, w/o Subsequent Messages } & & -0.0040 & & -0.0263 & & 1.3480 \\
\hline & & $(0.0077)$ & & $(0.1001)$ & & $(1.2777)$ \\
\hline (11) No Overdraft Mention = Auto-Pay Discount Only or Debit Card Discount Only & Omitted & Omitted & Omitted & Omitted & Omitted & Omitted \\
\hline p-value on F-test of equality between rows (2) and (3) & & 0.5931 & & 0.9344 & & 0.0371 \\
\hline$p$-value on F-test of equality between rows (2) and (4) & & 0.0738 & & 0.2454 & & 0.0206 \\
\hline $\mathrm{p}$-value on F-test of equality between rows (3) and (4) & & 0.2094 & & 0.2118 & & 0.7764 \\
\hline$p$-value on F-test of equality between rows (5) and (6) & 0.6183 & & 0.5858 & & 0.3359 & \\
\hline p-value on F-test of equality between rows (7) and (8) & & 0.3159 & & 0.9141 & & 0.0068 \\
\hline p-value on F-test of equality between rows (7) and (9) & & 0.0244 & & 0.0065 & & 0.0002 \\
\hline$p$-value on F-test of equality between rows (7) and (10) & & 0.0711 & & 0.0750 & & 0.0016 \\
\hline p-value on F-test of equality between rows ( 8 ) and (9) & & 0.1919 & & 0.0087 & & 0.2145 \\
\hline$p$-value on F-test of equality between rows ( 8 ) and (10) & & 0.3910 & & 0.0926 & & 0.5018 \\
\hline$p$-value on F-test of equality between rows (9) and (10) & & 0.5010 & & 0.1555 & & 0.4174 \\
\hline Observations & 108000 & 108000 & 108000 & 108000 & 108000 & 108000 \\
\hline \multicolumn{7}{|c|}{$\begin{array}{l}* * * p<=0.01, * * p<=0.05, * p<=0.10 \text {. Each column presents treatment effect estimates from a single OLS regression, with Huber-White standard errors, of the usage } \\
\text { measure in the column heading on the experimental variables in the rows. Variables in rows } 5-10 \text { identify the additive effect of one or more of the interest discount } \\
\text { arms; i.e., they identify the difference in treatment effects between the Overdraft Availability message and the Overdraft Interest Discount. Usage measures cover } \\
\text { September } 15 \text {-December } 31,2012 \text {. Account balances are in Turkish Lira, } 1 T L=\$ 0.56 \text { at the start of the experiment. Figure } 1 \text { summarizes the experimental design and } \\
\text { shows message scripts. Regressions also include controls for randomization strata. Unit of observation is the unit of randomization: a checking account. }\end{array}$} \\
\hline
\end{tabular}


Appendix Table 6: Effects of Overdraft Marketing on Number of Active Products During Experiment

\begin{tabular}{|c|c|c|c|c|}
\hline \multirow{2}{*}{ August 30th Message: } & \multicolumn{2}{|c|}{ Count } & \multicolumn{2}{|c|}{$\log$} \\
\hline & $(1)$ & $(2)$ & (3) & $(4)$ \\
\hline \multirow[t]{2}{*}{ (1) Overdraft Availability } & 0.0131 & 0.0131 & 0.0028 & 0.0028 \\
\hline & $(0.0136)$ & $(0.0136)$ & $(0.0047)$ & $(0.0047)$ \\
\hline (2) No Message & Omitted & Omitted & Omitted & Omitted \\
\hline \multicolumn{5}{|l|}{ September 15 Message: } \\
\hline (3) Overdraft Mention: identifies effect of & -0.0002 & -0.0002 & -0.0005 & -0.0005 \\
\hline Overdraft Availability message & $(0.0204)$ & $(0.0204)$ & $(0.0070)$ & $(0.0070)$ \\
\hline \multirow[t]{2}{*}{ (4) Overdraft Mention, with Interest Discount } & 0.0155 & & 0.0093 & \\
\hline & $(0.0192)$ & & $(0.0066)$ & \\
\hline \multirow[t]{2}{*}{ (5) Overdraft Mention, with Interest Discount only } & & 0.0145 & & 0.0074 \\
\hline & & $(0.0235)$ & & $(0.0081)$ \\
\hline \multirow[t]{2}{*}{ (6) Overdraft Mention, w/Interest + Auto-Pay Discounts } & & -0.0073 & & 0.0027 \\
\hline & & $(0.0234)$ & & $(0.0081)$ \\
\hline \multirow[t]{2}{*}{ (7) Overdraft Mention, w/Interest + Debit Card Discounts } & & $0.0393^{*}$ & & $0.0177^{* *}$ \\
\hline & & $(0.0236)$ & & $(0.0081)$ \\
\hline (8) No Overdraft Mention = & Omitted & Omitted & Omitted & Omitted \\
\hline \multicolumn{5}{|l|}{ Auto-Pay Discount Only or Debit Card Discount Only } \\
\hline Mean(LHS) & 2.6238 & 2.6238 & 0.6348 & 0.6348 \\
\hline $\mathrm{SD}(\mathrm{LHS})$ & $(2.27)$ & $(2.27)$ & $(0.78)$ & $(0.78)$ \\
\hline Observations & 108000 & 108000 & 108000 & 108000 \\
\hline
\end{tabular}

${ }^{* * *} \mathrm{p}<=0.01,{ }^{* *} \mathrm{p}<=0.05,{ }^{*} \mathrm{p}<=0.10$. Each column presents treatment effect estimates from a single OLS regression, with Huber-White standard errors, of the measure of the account holder's active products at the experimenting bank (including the checking account that is our unit of observation) in the column heading on the experimental variables in the rows. Variables in rows 4-7 identify the additive effect of one or more of the interest discount arms; i.e., they identify the difference in treatment effects between the Overdraft Availability message and the Overdraft Interest Discount. Figure 1 summarizes the experimental design and shows message scripts. Regressions also include controls for randomization strata. Unit of observation is the unit of randomization: a checking account. 